\title{
RISK AND EXPECTED RETURNS OF PRIVATE EQUITY INVESTMENTS: EVIDENCE BASED ON MARKET PRICES
}

\author{
Narasimhan Jegadeesh \\ Roman Kräussl \\ Joshua Pollet \\ Working Paper 15335 \\ http://www.nber.org/papers/w15335
}

\author{
NATIONAL BUREAU OF ECONOMIC RESEARCH \\ 1050 Massachusetts Avenue \\ Cambridge, MA 02138 \\ September 2009
}

We thank Steven Kaplan, Per Stromberg, and seminar participants at Stern School of Business, New York University, and Cornell University. We gratefully acknowledge financial support from Inquire UK and Inquire Europe. All errors remain our own. The views expressed herein are those of the author(s) and do not necessarily reflect the views of the National Bureau of Economic Research.

NBER working papers are circulated for discussion and comment purposes. They have not been peerreviewed or been subject to the review by the NBER Board of Directors that accompanies official NBER publications.

(C) 2009 by Narasimhan Jegadeesh, Roman Kräussl, and Joshua Pollet. All rights reserved. Short sections of text, not to exceed two paragraphs, may be quoted without explicit permission provided that full credit, including $\odot$ notice, is given to the source. 
Risk and Expected Returns of Private Equity Investments: Evidence Based on Market Prices

Narasimhan Jegadeesh, Roman Kräussl, and Joshua Pollet

NBER Working Paper No. 15335

September 2009

JEL No. G12,G24

\begin{abstract}
$\underline{\text { ABSTRACT }}$
We estimate the risk and expected returns of private equity investments based on the market prices of exchange-traded funds of funds that invest in unlisted private equity funds. Our results indicate that the market expects unlisted private equity funds to earn abnormal returns of approximately $1 \%$ per year. We also find that the market expects listed private equity funds to earn zero or marginally negative abnormal returns net of fees. Both listed and unlisted private equity funds have market betas close to one and positive factor loadings on the Fama-French SMB factor. Private equity fund returns are positively related to GDP growth and negatively related to the credit spread. In addition, we find that market returns of exchange traded funds of funds and listed private equity funds predict changes in self-reported book values of unlisted private equity funds.
\end{abstract}

Narasimhan Jegadeesh

Goizueta Business School

Emory University

1300 Clifton Road

Suite 507

Atlanta, GA 30322

and NBER

narasimhan_jegadeesh@bus.emory.edu

Roman Kräussl

FEWEB

VU University Amsterdam

de Boelelaan 1105

1081 HV Amsterdam

The Netherlands

rkraeussl@feweb.vu.nl
Joshua Pollet

Eli Broad College of Business

315 Eppley Center

Michigan State University

E. Lansing, MI 48824

pollet@msu.edu 


\section{Introduction}

Private equity (PE) refers to equity securities in private companies that are not publicly traded. Private equity funds that specialize in PE investments opened up this asset class to institutional investors and other capital market participants. The early successes of some large PE funds led to a rapid growth of this asset class. Capital commitment to private equity in the U.S. has grown rapidly from around \$20 billion in 1990 to over \$496 billion in 2007.

Although PE has experienced rapid growth, the risk and return profile of this asset class is not well understood. Many news stories in the media suggest that PE investments yield higher returns than traditional asset classes. ${ }^{1} \mathrm{~A}$ recent news release by Thomson Financial and the National Venture Capital Association announced that Thomson Reuters' US Private Equity Performance Index (PEPI) ${ }^{2}$ “across all horizons outperformed public market indices, NASDAQ and the S\&P 500, through 9/30/2008.” For example, for the 20-year period ending in September 2008, PEPI earned annualized return of $15.4 \%$ after fees, which is more than twice the return of 7.5\% earned by S\&P 500 .

A number of academic papers also report superior returns for private equity investments. Ljungqvist and Richardson (2003) find that private equity investments outperformed the S\&P 500 by more than 5\%. Cochrane (2005), Kaplan and Schoar (2005), Peng (2003) and others also find that private equity funds outperform the S\&P 500. However, these papers use databases that suffer from potential selection bias. Performance information is usually compiled from self-reported data provided by large private equity investors. It is quite likely that investors who do not have good experiences with their PE investments exit those investments or choose not to report their performance. Hence, PE funds that performed poorly are less likely to be included in these databases.

\footnotetext{
1 See Phalippou and Gottschalg (2009) for examples of several news articles that report high expectations for returns from PE investments. For example, the Financial Times (September 26, 2005) reports that a survey of large U.K. investors found that these "investors hope to make an average annual net return of 12.8 percent from their private equity investments."

2 See http://www.nvca.org/pdf/Q3_08_VC_Performance_Release.pdf. The Private Equity Performance Index (PEPI) is computed based on "quarterly statistics from Thomson Reuters' Private Equity Performance Database analyzing cash flows and returns for more than 1,900 US venture capital and private equity partnerships with a capitalization of $\$ 828$ billion. Sources are financial documents and schedules from Limited Partner investors and General Partners.”
} 
Moreover, the estimated performance of PE funds depends critically on the valuation of non-exited investments at the end of the sample period. For instance, Kaplan and Schoar use funds' self-reported values of such non-exited investments and find that the value-weighted performance of PE funds exceeds S\&P 500 return by about five percent per year. However, Phalippou and Gottschalg (2009) argue that it is more reasonable to write-off non-exited investments after a certain period of time and they find that PE funds underperform the market by three to six percent per year.

This paper examines the risk and return of private equity investments using market prices of two samples of publicly traded firms that invest in private equity. The first sample is publicly traded fund of funds (FoFs) that invest in private equity funds. Funds of funds accounted for $14 \%$ of global commitments made to private equity funds in 2006 according to Preqin, a research and consultancy firm focusing on alternative asset classes. FoFs that invest in unlisted PE funds are traded on many exchanges outside the US, including the London Stock Exchange and exchanges in Continental Europe. Since we observe market prices for these FoFs, we can determine the risk and return profile of the underlying PE funds from market prices.

The dataset we use has several advantages. First, it is free from selection bias. As Cochrane (2005) notes, "overcoming selection bias is the central hurdle" in evaluating the performance of PE investments. Moreover, we determine the value of investments from market prices and we do not rely on self-reported data for valuation. Therefore, we are able to circumvent critical shortcomings of self-reported data used in extant studies.

Our approach extracts an estimate of the market's ex-ante expectation of abnormal returns for PE investments from market prices. In contrast, the extant literature examines ex-post performances of unlisted PE funds. These studies find a wide range of abnormal returns, ranging from -6\% in Phalippou and Gottschalg (2009) to 32\% in Cochrane (2005). The findings in these papers provide interesting insights into past performances of PE funds in various datasets, based on different sets of assumptions. However, both investors and practitioners are interested in understanding what they can expect to earn in the long run through PE investments.

The intuition behind our approach is straightforward. The listed FoFs in our sample are structured as closed-end funds. The relation between the market prices of 
these FoFs and the amount they invest in unlisted PE funds provides a measure of the value added by the underlying PE funds. However, FoFs charge an extra layer of management fees and performance fees. After taking into account the present value of these fees, the market value of their equity invested in unlisted PE funds enables us to determine abnormal returns that the PE funds earn in the long run.

We present an analytically tractable model to determine the range of possible values for FoF fees based on the fee structure we observe in the data. The results of this model provide upper and lower bounds for abnormal returns that the market expects from investments in underlying PE funds. We find that the market expects PE funds to earn abnormal returns greater than $0.25 \%$ and less than $2.25 \%$ for a fund with the typical fee structure (e.g. base management fee of 1.5\% and incentive fee of 10\%) with discounts between 5\% and 19\%. We use simulations that capture the actual fee structure of each individual FoF as well as the observed fund discount to narrow the range of plausible abnormal return expectations. Our results indicate that the expected abnormal return is between $0.3 \%$ and $1.2 \%$. For a plausible range for the payout ratio of FoFs, i.e. from 0.3 to 0.5 , the ex ante estimate of the expected abnormal return is approximately $1 \%$. While the wide range of estimates in the existing literature is based on particular datasets used in the respective studies as well as additional assumptions, our results imply that the market does not expect PE funds to earn such extreme abnormal returns in the long run. Indeed, we find that any suggestion that the market expects either negative abnormal returns in the long run or positive abnormal returns in excess of three percent in the long run is inconsistent with the market prices that we observe.

We also examine risk and returns of publicly traded funds that invest in private equity. We refer to these funds as listed private equity (LPE). LPEs are similar to unlisted PE funds in several respects. The managers of LPEs are compensated through management fees and performance fees similar to unlisted PE funds. ${ }^{3}$ The LPEs also invest in private equity. These LPEs have the same opportunity sets as PE funds, to the

${ }^{3}$ From Gompers and Lerner (1999) and Kaplan and Schoar (2005) find that the compensation scheme for PE funds are relatively homogeneous with most funds using fee structure of $1.5-2.5 \%$ annual management fee and a $20 \%$ performance fees. 
extent that excess returns may be available to skilled investors who specialize in PE investments.

However, there are several organizational differences between LPEs and unlisted PE funds that may lead to differences in values that they are able to capture. For example, Jensen (2007) argues that unlisted PE funds' partnership structure may contribute to their value since they are not exposed to agency costs associated with diffusely owned publicly traded firms. Also, since PE funds have finite lives, they are committed to returning to their investors when they float funds in the future. Therefore, their reputational concerns provide them with an added incentive to perform. Since LPEs have an indefinite life, they are relatively insulated from such concerns. If any value that PE funds are able to add comes from the inherent incentives due to their organizational structure, then they would add more value than LPEs. Therefore, the return that the market expects LPEs to earn provides a lower bound on the returns unlisted PE funds would provide their LPs.

We are also able to determine the risk characteristics of PE investment since we have market prices available for all of the listed private equity vehicles in our database. The extant literature attempts to estimate the risk characteristics of PE investments based on their cash payouts to investors and based on the valuations of these investments when they raise follow-up capital. Because it is difficult to determine the market values of all investments made by PE funds based on cash payouts or additional financing rounds for some of their investments, additional assumptions are necessary to determine the risk of these investments. The estimates of systematic risk in this literature seem to depend significantly on these assumptions. For example, the estimates of beta range from about 0.5 in Hwang, Quigley, and Woodward (2005) to 4.66 in Peng (2001).

In related work, Martin and Petty (1983) and Brophy and Guthner (1988) use a samples of 11 and 12 listed venture capital funds, respectively, to examine their risk and ex-post returns over about a five-year period. Bilo, Christophers, Degosciu, and Zimmermann (2005) examine the risk and return characteristics of a larger sample of listed private equity. Although these studies use market prices of listed private equity investments, they also suffer from a selection bias since they require all firms in their samples to survive their entire sample period. 
Both listed and unlisted private equity funds in which FoFs invest have betas close to one and they have positive betas on Fama-French SMB factor. Private equity fund returns exhibit a positive correlation with GDP growth and negative correlation with credit spread. We also find that market returns of listed fund of funds and listed private equity predict future changes in self-reported book values of unlisted private equity funds. This result indicates that the performance of FoFs provides vital information about the performance of the unlisted PE industry.

The remainder of this paper is organized as follows: Section II describes the sample. Section III provides estimates of market's ex-ante expected abnormal returns for PE investments by unlisted PE funds and listed PE funds. Section IV examines the risk characteristics of the funds and Section $\mathrm{V}$ examines the sensitivity of PE investments to macroeconomic conditions. Section VI examines the ability of FoF and LPE returns to predict future changes in unlisted PE funds' self reported book values and Section VII concludes.

\section{Sample}

\section{A. PE Fund of Funds}

Unlisted PE funds are typically organized as limited partnerships. Outside investors have partnership interest in the funds as limited partners (LPs), and fund managers as general partners (GPs). PE fund of funds (FoFs) are intermediaries that raise funds from investors and invest in these PE funds as limited partners. In the US, only large institutions and qualified wealthy investors who meet certain minimum wealth and income criteria are allowed to invest in unlisted PE funds.

Many other countries, however, do not have similar restrictions. Therefore, although the PE funds typically impose minimum thresholds for LP investments, small investors in Europe can invest in unlisted PE funds through FoFs. Some of these FoFs are listed on European and Australian stock exchanges and they are actively traded.

First, we identify FoFs from the SDC Platinum database and obtained a list of FoFs from the Dow Jones Private Equity Funds of Funds database. Next, we augment this data with the list of components for the S\&P Listed Private Equity Index, PowerShares Listed Private Equity Fund, Power Shares International Listed Private Equity Fund, 
Listed Private Equity Index, and International Listed Private Equity Index. We match the names in this augmented list to the universe of traded stocks on Datastream. For the list of FoFs from these sources, we obtain annual reports from company websites and from industry sources for sample period (1994 to 2008). We examine each annual report to identify FoFs that invest at least 50\% of their capital in PE funds and our final sample contains 26 FoFs.

Table 1a and 1b present descriptive statistics for our sample of FoFs. Ten FoFs in the sample are listed in London, 14 are listed in continental Europe and two are listed in Australia. The FoFs range in market capitalization from $\$ 14$ million to $\$ 5.6$ billion over our sample period. The average market capitalization of FoFs during our sample period is \$314 million and the median is \$214 million. Twenty of the 26 FoFs indicate that their main focus is buyout PE funds. Although these FoFs are traded outside the US, 11 of them focus on investments in North America. In terms of the value of investments, $68.6 \%$ of the assets are managed by FoFs that focus on North America. Therefore, although the FoFs are listed outside the US, a significant part of their investments flow to North America. The annual reports of these FoFs indicate that these funds invest in a wide variety of unlisted PE funds raised by well-known PE groups. ${ }^{4}$ Since the median number of distinct unlisted PE funds held by each FoF is 28, the combined portfolio of all FoFs is a well-diversified portfolio of PE investments. The aggregate ownership by large investors, which is defined as investors with ownership of more than $3 \%$ of the shares outstanding, is about $47 \%$ on average. Therefore, even large investors invest through these vehicles.

\section{B. Listed Private Equity Funds}

Our primary source for listed private equity funds is the SDC Platinum database. The managers of LPEs classified as "funds" in the SDC data are compensated through management fees, as in the case of unlisted PE funds. ${ }^{5}$ Table 2 presents the descriptive

\footnotetext{
${ }^{4}$ Among others: Berkshire Fund VII, Blackstone Capital Partners V, Carlyle International Partners II, Goldman Sachs Capital Partners VI, KKR 2006 Fund, Lehman Brothers Venture Partners V, Vanguard VII, and Warburg Pincus Private Equity X.

${ }^{5}$ To check the completeness of the SDC database, we examine a sample of stocks that were not classified in the SDC database as "funds" but were included as components of LPE indices such as the S\&P Listed Private Equity Index. We find that stocks not classified in the SDC database as "funds" are holding companies for separate operating companies. The companies in this sample do not compensate their
} 
statistics for the sample of LPEs. There are a total of 129 LPEs in our sample. Ninety-two of these funds are listed in the London Stock Exchange and 16 are listed on US exchanges. The distribution of stage focus is much more diverse for LPEs than for FoFs.

\section{Expected abnormal returns from PE Investments}

We begin by analyzing the market's expectation of the abnormal return for unlisted PE investments. Earlier papers in this literature follow the traditional approach and examine the ex-post performance of unlisted PE funds. For example, Kaplan and Schoar (2005) and Ljungqvist and Richardson (2003) use cash inflows and outflows from samples of PE funds and investigate whether these funds outperformed their benchmarks.

Ex-post return is the sum of ex-ante expected return and unexpected return. One can appeal to rational expectations, and assume that the mean of the unexpected component of returns is zero, and use ex-post returns as an unbiased measure of expected returns. In most situations, ex-ante expected returns are unobservable and hence ex-post realized return is the only feasible route to estimate expected returns.

While ex-post return provides useful insights into past performance, it does not necessarily provide a measure of market's expectation of returns that would be earned in the long term through investments in PE funds. Even ignoring the issue of selection bias, past performance may have been biased by unexpectedly good outcomes during the sample periods in earlier studies. For example, PE funds that invested in start-up companies may have unexpectedly benefited from the Internet boom and the generally stellar performance of Internet stocks that are likely unique to the 1990s. Therefore, because such unexpectedly good outcomes dominated the sample period in many studies, it is likely that the ex-post returns are biased estimates of expected returns.

\section{A. An Analysis of Funds of Funds}

\section{A.1 Methodology}

The unique advantage with our FoF data is that we observe both the amount of money that the FoFs raise and their market value. The difference between the market value of the

managers using the typical PE management fee structure used by the companies classified as "funds" in the SDC database. 
FoFs and the amount of funds that FoFs invest in unlisted PE funds represent the net present value (NPV) of the underlying unlisted PE fund investments. We determine the abnormal returns that the market expects from PE fund investments based on the NPV of these investments.

While the economic basis for our methodology is straightforward, there are a few practical issues that we need to address. First, FoFs charge their own fees for managing the funds they raise. These fees are paid out of earnings from their investments, but the market capitalization of equity shares in the FoFs only reflects the present values of afterFoF fee cash flows. Therefore, the market value of the funds invested by the FoFs in underlying PE portfolio is the sum of the market capitalization of the traded shares of FoFs and the present value of FoF fees.

Figure 1 illustrates our approach. FoFs invest the amount they raise at the IPO (after issuance costs) in unlisted PE funds. This is the book value of the initial investment in PE. The unobserved market value of this PE investment has two components. The first component is the market value of FoF equity, i.e. the value of the investors' shares, and the second component is the value of FoF fees. The difference between the total market value of PE investments and the book value is the net present value of the underlying portfolio of PE investments. If the market expects positive abnormal returns from PE investments then the total market value is greater than the book value, as Panel A illustrates. However, if the market expects PE investments to earn negative abnormal returns then the total market value is less than the book value, as Panel B illustrates. Holding all else constant, the magnitude of the net present value reflects the magnitude of abnormal returns that the market expects the underlying PE funds to earn in the long run.

The computation of the market value of traded shares is straightforward since we have data on prices and number of shares outstanding. The calculation of the present value of FoF fees, however, is less straightforward since claims to these fees are not traded. We use two approaches to compute the present value of FoF fees and extract market expectation of abnormal returns for PE investments. In the first approach, we use a theoretical model to derive analytic formulas for the present value of the FoF fees as a function of the market value of traded shares and the fee structure. This model uses simplifying assumptions about the fee structure for analytic tractability. However, we 
show that we can use the results of this model and observed FoF discounts to determine upper and lower bounds on the magnitude of abnormal returns that the market expects PE funds to earn.

In the second approach, we incorporate the actual fee structure. Since this more general model is not analytically tractable, we use Monte Carlo simulations to compute the present value of FoF fees. We determine market's expectation of the abnormal return for PE fund investments using our simulation results and the observed average FoF discount.

\section{A.2 Market Value of Equity in FoFs}

The market value of FoF equity and the book value are key inputs for determining market's expectations of abnormal returns for PE investments. We get the most accurate measure of the amount that FoFs actually invest in PE funds at the time of the initial public offering (IPO) of each FoF since the amount invested is raised in cash that time. Therefore, in much of our analysis we will focus on valuation in the months immediately following the IPO.

We first examine the relation between market prices and post-IPO book value or the net asset value (NAV) of FoFs. Specifically, we examine the FoF discount at time $t$, defined as:

$$
\mathrm{D}_{\mathrm{t}}=1-\frac{\text { Price }_{\mathrm{t}}}{\mathrm{NAV}_{\mathrm{t}}} \text {. }
$$

We obtain prices and NAV data from Datastream. The NAV until the first financial statement after IPO is based on the value of funds raised at IPO. Since the NAV at this time accurately reflects the amount invested in underlying PE funds, we avoid any problems with self-reported NAVs of the underlying funds. As we progress through time, some of the investments get marked to NAV reported by the underlying PE funds.

However, in the early stages of a FoF's life, NAV is likely to be close to the dollar value of FoF investments since very few assets are marked up or down at that stage.

Table 3 presents the average discounts for FoFs over the first 12 months after their IPOs. Although the FoFs are issued at a premium at IPOs (to cover issuance costs), they trade at a discount of approximately 3\% three months after the IPO. The average 
discount gradually increases to approximately $12 \%$ by month 10 and fluctuates around this level for the remainder of the year.

FoF discounts follow a similar path as discounts for U.S. closed end funds that invest in publicly traded stocks and bonds in Weiss (1989) and Peavy (1990). Closed-end funds are also issued at a premium, but they eventually trade at a discount. Weiss and Peavy report that the closed-end fund discount stabilizes at about 10\% to $12 \%$ after six months subsequent to the IPOs. Since both FoFs and closed-end funds trade at substantial discounts, these funds are not expected to add sufficient value to justify their fees. Essentially, fund discounts imply that any additional value created by the abnormal returns that the underlying PE funds are expected to generate is not sufficient to offset the fees that the FoFs charge. To calculate a more precise estimate of the market's expectation about performance, we must take into account the present value of FoF fees in addition to the market value of FoF equity.

Predictable underperformance of FoFs subsequent to the IPOs indicates that the IPO price does not reflect the true value of the underlying PE investments net of FoF fees. The results in Table 3 indicate that the discount stabilizes towards the end of the first year. Indeed, subsequent tests indicate that we do not find any abnormal returns after the initial period. This evidence indicates that the price after one year is reliable measure of the true value of traded shares. Therefore, we use the evidence that FoF discount is about $12 \%$ to determine market's expectation of abnormal returns.

\section{A.3 Bounds on Expected Abnormal Returns}

In this subsection we analytically determine the present value of FoF fees as a function of the parameters of the fee structure, market's expectation of abnormal returns, and other factors. These analytical results provide upper and lower bounds on market's expectation of abnormal returns for the underlying portfolio of PE investments. As we show below, the distance between these bounds is fairly narrow and this range excludes many empirical estimates presented in the literature.

The FoF fees have a fixed component and an incentive component. ${ }^{6}$ The fixed component, or the base management fee, is specified as a fixed percentage of the assets

\footnotetext{
${ }^{6}$ In our sample, all FoFs have a base management fee and 19 out of the 26 FoFs have an incentive fee.
} 
managed by the FoF. The incentive component is specified as a percentage of profits that FoFs earn. The incentive fees are payable only if the NAV exceeds a high watermark, which is the highest NAV that the FoF had previously reached. Several funds also have a hurdle rate, and the incentive fee is payable as a percentage of the returns that exceed the hurdle rate. To make the model analytically tractable, we make some simplifying assumptions about the fee structure in this subsection. We assume that the fee structure comprises only a fixed fee and an incentive fee with no hurdle rate. We also assume in this subsection that the incentive fees are not subject to high watermark.

Our model is specified as follows. Let $N A V_{t}$ be the assets under management at time $t$ and let $\lambda$ be the base management fee expressed as a fraction of $N A V_{t}$. Let $R_{u, t}$ be the return of the underlying PE fund portfolio held by the FoF (gross of FoF fees). We assume that $\left\{R_{u, t}\right\}$ is independently and identically distributed. Let $\pi$ be the proportional incentive fee, which is computed as a fraction of the return after the base management fee is paid. Similarly, let $\theta$ be the proportional reinvestment rate (retention ratio), which is also computed as a fraction of the return after the base management fee. By construction, each FoF makes the following distributions at time $t+1$ :

$$
\begin{array}{ll}
\text { Base Managment Fee } & =\lambda N A V_{t} \\
\text { Incentive Fee } & =\pi N A V_{t}\left(R_{u, t+1}-\lambda\right) \\
\text { Distribution to FoF Shareholders } & =(1-\theta-\pi) N A V_{t}\left(R_{u, t+1}-\lambda\right) \\
\text { Retained Earnings } & =\theta N A V_{t}\left(R_{u, t+1}-\lambda\right),
\end{array}
$$

To ensure that investors receive positive distributions on average, the sum of retention ratio $(\theta)$ and the proportional incentive fee $(\pi)$ must be less than unity. Consequently, the retention ratio has a range from zero to $1-\pi$ and the payout ratio (1- $\theta$ ) has a range from $\pi$ to unity. In this context, the payout ratio is the proportion of $N A V_{t}\left(R_{u, t+1}-\lambda\right)$ that is distributed to investors or paid to the manager as the incentive fee. Given these distributions, the evolution of the net asset value is:

$$
N A V_{t+1}=\left(1+\theta\left(R_{u, t+1}-\lambda\right)\right) N A V_{t}
$$

In general, the base management fee inherits some of the underlying fund risk as long as the fund retains a portion of its earnings for reinvestment. However, if all earnings are 
paid out as distributions to managers and shareholders, i.e. if $\theta=0$, then the base management fee is riskless.

In addition to the simplifying features of the fee structure that we discussed earlier, the distribution we specify above also deviates from the actual fee structure if $\left(R_{u, t+1}-\lambda\right)<0$. Implicitly, this specification assumes that the FoF manager pays the fund if the fund return is lower than $\lambda$. However, FoF managers do not make such payments in practice. Instead, the high watermark condition reduces subsequent incentive compensation by the amount corresponding to any return shortfall. While our assumption is analytically appealing, it changes the timing of cash flows to managers and understates the value of the incentive fee to the managers due to the time value of money. Therefore, we relax this assumption in our simulation analysis (see next subsection) to address any potential issues related to this bias.

Our valuation model assumes that the expected returns are for all traded claims are determined by CAPM. Let $\alpha$ be the abnormal return that the market expects the underlying PE funds to earn. Therefore, the expected return for the underlying PE is: ${ }^{7}$

$$
E_{t}\left[R_{u}-R_{f}\right]=\alpha+\beta_{u}\left(E_{t}\left[R_{m}\right]-R_{f}\right)
$$

where $\beta_{u}$ is the underlying fund beta, $E_{t}\left[R_{m}\right]$ is the expected return on the market, and $R_{f}$ is the riskfree rate. ${ }^{8}$ We assume that all of these moments are constant for convenience.

The parameters of the model must satisfy two technical conditions. First, $\alpha-\lambda+R_{f}>0$ to guarantee that the expectation of the risk-adjusted distribution to investors is positive, i.e., the cash flows that investors receive have positive economic value, and consequently, the price of the asset is strictly positive. ${ }^{9}$ Second,

\footnotetext{
${ }^{7}$ Since PEs make investments at privately negotiated prices, the expected returns from their investments can deviate from CAPM expected returns depending on thier skill.

${ }^{8}$ Note that the return earned by the underlying portfolio is defined in this context using the quantity of money invested in the PE funds and not the market value of the underlying portfolio. The market value of the portfolio of underlying PE investments would incorporate the effect of any anticipated outperformance, and hence, in an efficient market the expected abnormal returns based on the market value of the underlying PE portfolio would be zero.

${ }^{9}$ In our sample, the average base management fee equals $1.5 \%$ and the average riskfree rate equals $6 \%$. Unless PE funds are expected to earn large negative abnormal returns, the condition $\alpha-\lambda+R_{f}>0$ holds.
} 
$R_{f}-\theta\left(\alpha-\lambda+R_{f}\right)>0$ to guarantee that the transversality condition is satisfied, i.e., the value of the equity stake is finite because the risk-adjusted distributions do not grow faster than the riskfree rate.

The present value of FoF equity $V_{e, t}$ is:

$$
V_{e, t}=E_{t}\left[\sum_{s=1}^{\infty} \frac{(1-\theta-\pi)\left(R_{t+s}-\lambda\right) N A V_{t+s-1}}{\left(1+E_{t}\left[R_{e}\right]\right)^{s}}\right]
$$

where $E_{t}\left[R_{e}\right]$ is the discount rate for equity. Since distributions to shareholders are made after payment of base management fees, $E_{t}\left[R_{e}\right]$ will usually be different from the discount rate for the underlying PE funds.

Proposition 1 below provides an analytic solution for the present value of investor's claims that is stated in terms of the fund discount as well as an expression for the endogenously determined value of $E_{t}\left[R_{e}\right]$.

Proposition 1. The FoF discount and the associated discount rate for equity are specified by the following two equations:

$$
D_{t}=1-\frac{V_{e, t}}{N A V_{t}}=1-\frac{(1-\theta-\pi)\left(\alpha-\lambda+R_{f}\right)}{R_{f}-\theta\left(\alpha-\lambda+R_{f}\right)}
$$

and

$$
E_{t}\left[R_{e}\right]=R_{f}+\left(\frac{R_{f}}{\alpha-\lambda+R_{f}}\right) \beta_{u}\left(E_{t}\left[R_{m}\right]-R_{f}\right) .
$$

Proof: See appendix.

The first expression indicates that the FoF discount is a decreasing function of the expected abnormal return and an increasing function of both the base fee and the incentive fee. The expression for the discount rate for equity implies that the systematic risk for the net-of-fee return is a scaled version of the systematic risk for the underlying portfolio. Since the base management fee is a fixed proportion paid before the distribution to shareholders, this obligation is similar to a debt obligation and magnifies the risks borne by equity holders. Therefore, the base fee increases the systematic risk faced by investors holding all else constant. Interestingly, the expression for the discount 
factor also indicates that the proportional reinvestment policy does not change the systematic risk of the investors' claims.

We also determine the present value of the incentive fees, $V_{i, t}$. Since the ratio of the incentive fee to the distribution to investors is $\pi /(1-\theta-\pi)$, Proposition 1 implies that $V_{i, t}$ is given by:

$$
\frac{V_{i, t}}{N A V_{t}}=\frac{\pi\left(\alpha-\lambda+R_{f}\right)}{R_{f}-\theta\left(\alpha-\lambda+R_{f}\right)} .
$$

The discount rate for the incentive fee, $R_{i}$, is equal to the discount rate for the distributions to investors. Both investors and fund managers have claims that are a fixed proportion of the underlying distribution net of the base fee.

Although the fee structure in the model makes simplifying assumptions, the results we derive in this subsection provide upper and lower bounds on market's expectation of abnormal returns under the actual fee structures we observe in practice. First, we determine a lower bound. We proceed by addressing the following question. Given the level of FoF discount observe, what is the lowest possible level of market's expectation of abnormal returns?

As we discussed in the context of Figure 1, the difference between the NAV and the total market value of FoF investments is positively related to the expected abnormal return. We observe the NAV and the market value of equity. The only unobservable component of total market value is the value of FoF fees. For any given value of NAV and market value of equity, a smaller value of FoF fees would imply a smaller expected abnormal return. Therefore, if we find a lower bound for the value of FoF fees, then we also have a lower bound for the expected abnormal return. If we assume that the incentive fee is zero, i.e. $\pi=0$, then we have a lower bound for FoF fees. In addition, this assumption also implies that the hurdle rate and high watermark condition are irrelevant. Rearranging Equation (6) and setting $\pi=0$, yields the following lower bound $\alpha_{l}$ :

$$
\alpha_{l}=\lambda-R_{f}+R_{f}\left(\frac{1-D_{t}}{1-\theta D_{t}}\right)
$$

We use the same intuition to find an upper bound for the expected abnormal return as well. If we find an upper bound for the value of FoF fees, then there exists a 
corresponding upper bound for $\alpha$. The value of FoF fees without a hurdle rate will be greater than the value with a positive hurdle rate. Since the hurdle rate in practice is nonnegative, the present value of incentive fee is an upper bound on the present value of the incentive fee in practice. ${ }^{10}$ Therefore, the $\alpha$ in Equation (6) is itself an upper bound for the expected abnormal return because this equation was derived while ignoring the hurdle rate. Specifically, we get following upper bound $\alpha_{h}$ by rearranging Equation (6):

$$
\alpha_{h}=\lambda-R_{f}+R_{f}\left(\frac{1-D_{t}}{1-\pi-\theta D_{t}}\right) .
$$

The average discount in Table 3 twelve months after FoFs' IPOs is about $12 \%$ and the two standard deviation confidence interval around this point estimate ranges from 5\% to $19 \%$. Figure 2 plots that upper and lower bounds of $\alpha$ when the discount equals the point estimate of $12 \%$ and for discounts of $5 \%$ and $19 \%$, which are the extreme points of the confidence interval. In this figure we set the risk-free rate $\left(R_{f}\right)$ equal to $6 \%$ (the historical average yield for long-term bonds during our sample period) and the base management fee $(\lambda)$ equal to $1.5 \%$ (the average base management fee in our sample). To determine the upper bound we also set the incentive fee $(\pi)$ equal to $10 \%$ (the average incentive fee for FoFs that have an incentive fee). This value of $\pi$ overstates the average incentive fee for our sample because the sample includes FoFs that do not charge any incentive fees. Hence, it provides an upper bound compared to the average incentive fee for the full sample (including FoFs that do not have any incentive fee).

Since the bounds are a function of market's expectation of the retention ratio $(\theta)$ Figure 2 presents the bounds for payout ratios $(1-\theta)$ ranging from 0.25 to 1 . The average payout ratio during the sample period is approximately 0.3 , but this average is not necessarily the market's expectation of the ratio in the future. Because many of the

\footnotetext{
10 This discussion overlooks the mismatch between the timing of incentive fee payments in the model compared to standard practice whenever the underlying portfolio return is sufficiently low. The value of incentive component of the management fee is understated due to the time value of money because negative incentive payments in the model are delayed in the real world to offset subsequent profits. However, for sufficiently high hurdle rates, disregarding the hurdle rate in the model more than counterbalances this understatement. Using our simulations we verify that Equation (10) does provide an upper bound on the market's expectation of management skill for the average hurdle rate in the sample.
} 
funds in our sample are early in their life cycle, they may have artificially low payout ratios during this time period.

We plot these upper and lower bounds as a function of the payout ratio for the three different valuation levels. Figure 2 indicates that the lower bound for $\alpha$ is always greater than $0.25 \%$ and the upper bound is always less than $2.25 \%$. The difference between the upper and lower bounds on $\alpha$ for a given discount level and payout ratio is less than $1 \%$. Thus, the model produces a relatively narrow range for the market's expectation of $\alpha$ relative to the wide range of estimates offered in the literature. This range, however, indicates that the market considers PE investments as positive NPV projects net of the fees charged by the underlying PE funds. Hence, we rule out negative expected abnormal returns.

\section{A.4 Expected Abnormal Returns - Simulation Results}

This subsection presents simulations designed to determine the market's expectation of the abnormal return for unlisted PE funds. The simulations incorporate the hurdle rate and the high watermark features of the typical FoF fee structure that we observe in practice. They also correctly account for the fact that incentive fees are non-negative even if the underlying portfolio earns a negative return.

Our simulation methodology requires the selection of several parameter values. We assume that the riskfree rate is equal to $6 \%$, based on the average Treasury bond rate during our sample period. We also assume the market risk premium is $4 \%$ and the standard deviation of stock market returns is $15 \%$ per year. In addition, we assume that $\beta=1$ for the underlying PE investments and that the fund-specific standard deviation is $15 \%$ per year. We choose these parameters to be consistent with the actual values we observe in the data and we note that the results are not particularly sensitive to these parameter values.

We simulate the annual return for the underlying portfolio of each fund using the single factor model with an adjustment for the level of the expected abnormal return. Each component of this annual portfolio return is drawn independently and identically over time from a normal distribution. We calculate the base management fee and the incentive fee using fund-specific base management rate, incentive rate, and hurdle rate 
for each particular fund. The base fee is a fixed proportion of the underlying portfolio value at the beginning of the period that is collected by the fund manager at the end of each period. The incentive fee is the maximum of a fraction of the underlying portfolio proceeds minus the base management fee that is above the hurdle rate and zero. The incentive fee is subject to the typical hurdle rate and high watermark provisions. The payout ratio, in conjunction with the fund-specific base management rate, determines the distribution to investors. The lower bound of the distribution to investors is zero. Each fund reinvests the residual after all fees and distributions, i.e. retained earnings, in the underlying portfolio for the next period. Each sample path for returns is simulated for 300 years and we repeat this process 5,000 times for each fund, holding the expected abnormal return and payout ratio constant.

We calculate the present value of all distributions to investors using a constant discount rate. The discount rate for the distribution to investors depends on the systematic risk of these distributions. Since we derive the relevant theoretical beta in the last section under simplifying assumptions, the theoretical beta does not reflect the true beta for these distributions when we include the hurdle rate and high watermark provisions. Instead, we find the appropriate beta for these distributions using an iterative methodology.

We use the betas from the analytical solution in the last subsection as the starting point. Next, we calculate the return for each period using the present value of subsequent distributions at the beginning of the current period, the present value of subsequent distributions at the beginning of the subsequent period, and the distribution at the end of the period. Then we use this return series and regress it on the simulated market return series. The coefficient estimate from this regression is the next iterative estimate for beta. We continue this process until difference between consecutive iterative estimates for beta is less than 0.001 , i.e., the sequence converges. Once we have the appropriate beta for the distributions to investors for a particular fund, we calculate the relevant discount rate and the present value of these distributions for each sample path. We average these present value calculations and then we compute the simulated discount for the fund. We repeat 
this exercise for the expected abnormal return ranging from -3\% to $3 \%$ in increments of $1 \%$ and for the payout ratio ranging from 0.25 to 1 in increments of $0.05 .^{11}$

Table 4 presents the simulated average of FoF discounts across funds for the expected abnormal return ranging from $-2 \%$ to $2 \%$ and various levels of the payout ratio. As we would anticipate, the average fund discount decreases as $\alpha$ increases because investors will be willing to pay more if they expect the underlying PE funds to earn higher returns holding all else constant. For a relatively low expected abnormal return, the discount decreases with the payout ratio. For example, if $\alpha$ is equal to $-2 \%$, the average discount is $62 \%$ for a payout ratio of 0.25 compared to a discount of $28 \%$ when the payout ratio is 1 . Intuitively, if abnormal performance is low relative to FoF fees, the market would prefer that each fund increase its payout ratio because reinvestment destroys value.

Analogously, the discount increases or the premium decreases with the payout ratio for large expected abnormal returns. For example, if $\alpha$ is equal to $2 \%$, the average premium is $18 \%$ if the payout ratio is 0.25 compared to a premium of only $2 \%$ if the payout ratio is 1 . This result is also intuitive. The market would prefer that each fund decrease its payout ratio whenever abnormal performance is high relative to FoF fees because reinvestment in the underlying PE funds is a positive NPV project. Hence, the simulations indicate that high reinvestment magnifies the impact of abnormal performance relative to FoF fees.

What levels of $\alpha$ are consistent with the observed level of the average FoF discount that we observe in Table 3? Each curve in Figure 3 plots the simulated FoF discount for a given expected abnormal return as a function of the payout ratio, i.e. each curve is an iso- $\alpha$ curve. The horizontal line in Figure 3 reflects the statistical average FoF discount of $12 \%$. Each intersection of an iso- $\alpha$ curve with this horizontal line is a possible combination of the expected abnormal return and the payout ratio that is consistent with market prices.

This figure indicates that there is a relatively narrow range of possible expected abnormal returns that are consistent with the observed FoF discount of $12 \%$. First, we

\footnotetext{
${ }^{11}$ Since some funds have an incentive fee of $20 \%$, the lower bound for the payout ratio of these funds must be greater than 0.2 (or 20\%).
} 
consider the plausibility of substantial negative expected abnormal returns. Figure 3 indicates that if the market expects the underlying PE funds to have an average abnormal return of less than $-1 \%$ per year, the FoF discount would be then at least $20 \%$ which is more than two standard deviations greater than our point estimate of $12 \%$. Hence the estimates of $-6 \%$ to $-3 \%$ abnormal returns in Phalippou and Gottschalg (2009) are significantly smaller than the market's ex-ante expectation. Indeed, the horizontal line at a discount of $12 \%$ is always below the iso- $\alpha$ for $\alpha=0$, and hence, the market expects positive abnormal returns from the underlying portfolio of PE funds.

Figure 3 also implies that if $\alpha$ is greater than or equal to $2 \%$, FoFs would trade at a premium, rather than a discount, for any expectation of the payout ratio. Intuitively, if $\alpha$ equals $2 \%$, then the abnormal returns PE funds earn will more than compensate for FoF fees. In this case, the smallest possible premium is $2.3 \%$ (discount of $-2.3 \%$ ), i.e, more than four standard deviations away from the average discount of $12 \%$. Therefore, many of the large estimates of $\alpha$ in the literature based on ex-post performance are much greater than the level anticipated by the market.

While Figure 3 does not extend the curves to include payout ratios lower than 0.25 due to technical restrictions imposed by the large incentive fees of some FoFs in the sample, analyzing such a payout ratio for funds with lower incentive fees would not change our findings. Note that iso- $\alpha$ curves outside the range of $0 \%$ and $2 \%$ diverge from the horizontal line as the payout ratio decreases to 0.25 . This divergence pattern would continue for lower payout ratios because the impact of abnormal performance relative to fees is magnified by reinvestment. Hence, our results indicate that the market expects $\alpha$ to be between 0 and $2 \%$ regardless of the market's expectation of the payout ratio. If we consider a plausible payout ratio range, such as 0.3 to 0.5 , a more detailed version of Figure 3 would indicate that the expected abnormal return is bounded between $0.8 \%$ and $1.2 \%$, or approximately $1 \% .^{12}$

\section{B. An Analysis of Listed Private Equity Funds (LPEs)}

\footnotetext{
${ }^{12}$ We also examined the simulated discount for a range of alternative parameter values for market volatility and the risk premium. These variations do not dramatically change the pattern of results.
} 
This section examines whether LPEs add value. LPEs and PE funds have similar operational focus since they both invest in private equity. LPE managers are also compensated through management fees and at least in some cases, with incentive fees. However, there are several differences in the organizational structure that could lead to performance differences between LPEs and PEs. Since LPEs are closed end funds with indefinite life they do not have the same reputational concerns as PE funds. In fact, the typical discount in the case of closed-end fund suggests that the organizational structure of LPEs would result in agency costs such as unduly high fees or less than optimal effort on the part of fund managers.

In contrast, several papers have argued that PE funds' incentive structure aligns their interests with that of limited partners. Also, since PE funds have finite life, they are committed to returning to their investors for funds they float in the future and reputational concerns provide them with an added incentive to perform. Therefore, the organizational structure of PE funds may incentivize them to add more value than that of LPEs.

Since LPEs likely suffer from higher agency costs, we would expect them to underperform PE funds. Since they both operate in the same PE space, but LPEs have higher agency costs, the expected performance of LPEs provides a lower bound on the expected performance of PE funds. The difference between the expected performances of LPEs and PEs would provide a quantitative measure of the agency costs.

To investigate whether the market expects LPEs to earn abnormal returns, we examine the discounts for these LPEs soon after their IPOs. As we discussed earlier, discounts ratio based on the IPO price are likely to be a biased indicator of market expectations. Therefore, we first examine the pattern of LPE discount in event time after IPOs. We use the beginning of the first month when data are available on Datastram as the IPO date.

Table 5 presents the discount over the first 12 months after IPOs. LPEs trade on average at a $4 \%$ premium to NAV at the end of their first month. However, the premium declines to about $1.9 \%$ by the end of six months. By the end of 12 months after IPO, the LPEs trade at a discount of $1.7 \%$. These results indicate that although the IPO premium disappears by the end of 12 months, LPE price is close to its NAV. Therefore, the market expects LPEs to have abnormal returns close to zero. 


\section{Risk Characteristics of FoFs and LPEs}

The extant literature provides a wide range of estimates for systematic risk of PE investments. For example, the estimates of beta range from about 0.5 in Hwang et al. (2005) to 4.66 in Peng (2001). This wide range illustrates the difficulty in estimating betas for these investments. To a large extent, the difficulty arises from the fact that these studies estimate betas from investment cash flows rather than from market prices. As result, the beta estimates depend on the underlying assumptions.

In turn, the difficulty in estimating the risk of PE funds precludes the reliable evaluation of the performance of PE funds. For example, Phalippou and Gottschalg's (2009) analysis show that the measured performance is quite sensitive to reasonable changes in assumptions about beta. In their sample, the abnormal returns for PE funds changes from $-3 \%$ per year when they assume beta is equal to one, to $-6 \%$ per year when they assume an "industry/size-matched cost-of-capital."

This section examines the systematic risk of FoFs and LPEs. Since we have market prices, we are able to estimate multiple dimensions of risk using traditional time series regressions. This section present systematic risk measured with respect single factor and multifactor models. In addition, we also present the sensitivity of FoF and LPE performances to macroeconomic risks. To examine the systematic risk of PE investments, we construct value-weighted indices of FoFs and LPEs. Each month we include all funds in the relevant group with the necessary price and return information.

\section{A. Market Risk and Fama-French Factor Risks}

We examine systematic risk in the context of CAPM and the Fama-French (1993) and Carhart (1997) four-factor models. Since our FoF and LPE samples comprise international funds, we use MSCI world index as the appropriate proxy for the market factor. We also examine the systematic risk with respect to the S\&P 500 index to examine the sensitivity of our indices to US markets. We fit the following time series regressions to estimate systematic risk:

$$
R_{i, t}-R_{f, t}=\alpha_{i}+\beta_{i, m}\left(R_{m, t}-R_{f, t}\right)+\beta_{i, s m b} S M B_{t}+\beta_{i, h m l} H M L_{t}+\beta_{i, m o m} M O M_{t}+\varepsilon_{i, t},
$$


where $R_{i, t}$ is the fund index return and $R_{f, t}$ is the risk-free rate. We use one-month U.S. Treasury Bill rate as risk-free rate. $S M B, H M L$, and $M O M$ are the size, book-to-market and momentum factor portfolios. We obtain factor portfolio returns from Kenneth French's website. We note that these three factors are constructed only from US stocks. Given the international composition of fund portfolios, we would ideally like to use international factors but we are constrained to use US factors because we do not have international factor data. Nevertheless, since the US equity market is the largest part of any world portfolio, the sensitivity of the fund indices to the US factors will shed important insights into the nature of PE risk.

Table 6 presents the regression estimates and corresponding Newey-West standard errors with six lags. Betas with respect to the MSCI World index for the FoFs and LPEs are 0.93 and 0.84 , and with respect to the S\&P 500 index are 0.80 and 0.71 , respectively. The $R^{2} \mathrm{~s}$ are also larger with respect to the MSCI index. Since the underlying funds have international exposures, both FoF and LPEs have higher sensitivity to the MSCI World index, and the MSCI index has a larger explanatory power than the S\&P 500 index.

Table 7 presents the regression estimates for the four-factor model. With the MSCI index as the market factor, the betas with respect to the SMB factor are 0.44 and 0.54 for the FoF and LPE indices respectively, and both these estimates are significantly greater than zero. Therefore, both FoFs and LPEs behave more like small firms than large firms. This finding is intuitive since many of the PE investments are made in firms that are smaller than a typical listed firm.

The beta with respect to HML is 0.35 for FoFs and 0.39 for LPEs. Although these point estimates are not significantly different, HML beta is not significantly different from zero for FoFs but it is significant for LPEs. Therefore, both FoFs and LPEs are more sensitive to value firms than growth firms. One possible explanation for this finding is that these funds have significant investments in buyouts and targets of buyouts are perhaps more likely to be value firms than growth firms. In unreported results, we examined the betas from a four-factor model separately for funds with buyout focus and venture capital (VC) focus. We found that buyout funds' HML beta estimate was 
significantly positive but VC funds' HML beta estimate was not significantly different from zero. Therefore, even VC funds on average are not sensitive to the growth factor.

Overall, we find that the risk profiles of FoFs and LPEs are quite similar. The betas with respect to various risk factors are not statistically different for these two categories of funds. Although the geographic composition of the FoFs and LPEs are different, the similarities indicate that their risk structures are not particularly different.

As we discussed earlier, private PE funds and LPEs differ in their organizational structure because LPEs have indefinite life while PE funds have finite life and they are likely to be more sensitive to reputational concerns because they are constrained to periodically go back to the market to raise funds for future operations. Our earlier findings indicate that PE funds add more value than LPEs, which is likely due to this organizational difference. However, this difference between PE funds and LPEs need not necessarily affect their risk exposure since they operate in the same space.

Our analysis of the implications of the FoF fee structure showed that FoF equity might be viewed as a levered claim on the underlying PE funds because the base management fee is equivalent to debt contract. Therefore, the market beta of FoF equity provides an upper bound for the market beta of the underlying portfolio of PE funds.

Conceptually, we could "unlever" the FoF betas based on our analysis in Section III. The practical impact of accounting for the implicit leverage effect due to the base management fee, however, may not be as large. For example, Kaplan and Stein (1990) find that the even when firms increase the debt in their capital structure from about 25\% of their capital to about $81 \%$ the change in equity betas is "surprisingly small." Therefore, the true betas of the underlying PE funds may be closer to the FoF equity betas than what is suggested by the leverage effect due to base management fee.

In earlier work, Kaplan and Schoar (2005) acknowledge the difficulty in estimating betas because of "the lack of true market values for fund investments until the investments are exited" and assume that beta equals one. Phalippou and Gottschalg (2009), however, conjecture that "the assumption of a beta as 1 is likely to overstate relative performance" and they use an industry/size-matched cost-of-capital benchmark. However, our findings indicate that the betas for FoFs and LPEs are not significantly different from one. 


\section{B. Alphas}

The alphas for FoFs and LPEs are on average not different from zero both with CAPM and four-factor benchmark. These results indicate that these funds on average performed as expected, conditional on the realizations of the risk factors. Essentially, the market was not surprised ex-post by the performance of this asset class. Thus, the discount one year after the IPO does not appear to be biased by any systematic error in the expectations of market participants. We would like to caution that these estimated alphas should not be used as a measure of whether or not PE investments themselves are able to earn abnormal returns. In an efficient market, the market would anticipate any potential ability of PEs to earn abnormal returns above their cost of capital, and this ability will be reflected in market prices. Therefore, the market price-based returns earned by PEs should only compensate investors for systematic risk.

\section{FoF and LPE Performance and Economic Environment}

This section examines the relation between fund performance and macroeconomic activity. We use US GDP growth and credit spread to capture macroeconomic activity and we fit the following regression:

$$
R_{i, t}-R_{f, t}=\alpha_{i}+\beta_{i, m}\left(R_{m, t}-R_{f, t}\right)+\delta_{i, G D P} \Delta G D P_{t}+\delta_{i, \text { credit }} \text { Credit Spread }_{t}+\varepsilon_{i, t}
$$

where $\triangle G D P$ is percentage real GDP growth and credit spread is the difference between the yield on BAA and AAA rated corporate bonds. ${ }^{13}$ For ease of interpretation, we standardize both $\triangle G D P$ and Credit Spread by demeaning them and dividing them by their respective standard deviation. Therefore, the slope coefficients denote fund returns for one standard deviation change in these variables. We use MSCI world index as the market portfolio in the results we report. ${ }^{14}$

GDP growth would have a positive impact on fund performance after controlling for contemporaneous market returns if macroeconomic risk have a greater effect on early

\footnotetext{
13 We obtain the data regarding macroeconomic activity from the St. Louis Federal Reserve website.

14 We find similar results when we use the S\&P 500 index as the market portfolio. In addition, IPO volume is not significantly related to the performance of the FoF index or the LPE index after controlling for GDP growth and the credit spread and the inclusion of IPO volume does not qualitatively change the estimates for the other regressors.
} 
stage firms than on large cap firms that form a large part of the market index. Healthy GDP growth could potentially allow private firms to access capital markets and go public, which would have a positive impact on PE investments.

However, economic growth also could attract greater competition. For instance, Gompers and Lerner (2000) find that valuation becomes richer and hence the increased competition that comes with economic growth may have a negative impact on fund performance. Kaplan and Schoar (2005) report that funds started when there is increased competition tend to underperform other funds, and find support for hypothesis that performance suffers when money chases deals. The net effect of the positive impact of economic growth and the negative impact of increased competition on the cost of future investments depends on which of these effects dominate.

Credit spread also provides a measure of the economic environment. Koopman, Kräussl, Lucas, and Monteiro (2009), among others, show that credit spread is countercyclical. As Fama (1990) argues, widening spread generally signals deteriorating business conditions, which would make it difficult times for private firms to go public. Moreover, widening credit spread also increases the cost of raising new debt and hence it would likely have an adverse impact on the performance of private firms. Therefore, we expect a negative relation between the performance of PE funds and credit spread.

Table 8 reports the estimates for equation (12). We find that GDP growth is positively related to returns for both FoFs and LPEs. One standard deviation change in GDP growth leads to $2.04 \%$ and $1.29 \%$ increase in excess returns for FoFs and LPEs, respectively. Our results indicate that the increase in the value of existing investments of PE funds more than offset the negative impact of potentially increased competition on returns from future investments.

We also find that credit spreads are negatively related to FoF and LPE returns, after controlling for market returns and also after accounting for GDP growth. FoFs are more sensitive to credit spreads than LPE and the difference in the slope coefficients is significant at the five percent level. One possible explanation for this difference is that because the PE funds that underlie FoF investments may be hurt more by deteriorating capital markets because of their finite life. The LPEs may not have the same urgency to 
liquidate their investments in unfavorable market conditions as PE funds because of their indefinite life.

\section{PEPI and Fund Indices}

Practitioners and industry sources such as the National Venture Capital Association use the Private Equity Performance Index (PEPI) to measure the performance of PE funds. Thomson Reuters computes PEPI based on cash flows from the PE funds in the Thomson database, based on self-reported book values of these funds. As Phalippou and Gottschalg (2009) and others have noted, self-reported book values tend to be overstated.

Any bias aside, self-reported book values may not reflect changes in their market values in a timely manner. For instance, book values reported by funds may only partially adjust to changes in their true value. Under this partial adjustment hypothesis, PEPI would not reflect true changes in the value of PE investments in a timely manner since smoothed book values are used to compute PEPI.

In contrast to PEPI, we compute the FoF and LPE indices using market prices. Since market prices reflect fundamental values in a timely manner, these indices should be able to predict changes in PEPI under the partial adjustment hypothesis. To examine whether FoFs and LPE indices can predict future changes in book values that underlie PEPI, we examine the relation between PEPI returns and contemporaneous and lagged values of MSCI World index returns and fund index returns.

Table 9 reports the regression results. Since PEPI is published quarterly, we fit the regressions with quarterly returns. The slope coefficient in univariate regression with MSCI as the independent variable is 0.39 , which is statistically significant. This slope coefficient is significantly smaller than the analogous coefficient for FoFs, which may be due to the fact that PEPI is computed using data from PE funds that largely invest in US companies, while the FoFs invest in international PE funds. Partial adjustment of book values used in the computation of PEPI will also result in a smaller slope coefficient because the slope coefficient estimate for contemporaneous returns will understate the true sensitivity of PE funds to the stock market.

To test the delayed adjustment hypothesis, we include both the contemporaneous and lagged MSCI World returns in the regression specification. In addition, we also add 
contemporaneous and lagged returns on the FoF index as additional explanatory variables. Since FoF returns reflect changes in the value that are unique to the PE sector, lagged FoF returns should be able to incrementally predict PEPI returns under the delayed adjustment hypothesis.

The results in column 6 of Table 9 indicate that the slope coefficients on lagged MSCI World and FoF index returns are at 0.09 and 0.11, respectively, both statistically significant. Therefore, both lagged MSCI World and FoF index returns are useful in predicting PEPI returns. In fact, the predictive power of lagged FoF index return is at least as strong as that of lagged MSCI World index returns although the FoF index returns in much noisier since it is constructed with only 26 FoFs. We found similar results when we used LPE index returns in the place of FoF index returns. These results support the delayed adjustment hypothesis and imply that this index provides crucial information about the performance of the unlisted PE industry.

\section{Conclusion}

We estimate the risk and expected returns on private equity investments based on the market prices of exchange traded funds of funds that invest in unlisted private equity funds. We also examine the risk and expected returns of listed private equity funds. Our results indicate that the market expects unlisted private equity funds to earn abnormal returns of about zero to two percent. We also find that the market expects listed private equity to earn zero to marginally negative abnormal returns net of their fees.

Earlier studies document abnormal returns for unlisted PE funds that range from 6\% (e.g Phalippou and Gottschalg, 2009) to +32\% (Cochrane, 2005). While these estimates are based on the datasets used in the respective studies and additional assumptions, our results indicate that the market does not expect PE funds to earn such extreme abnormal returns in the long run. In fact, we show that any proposition that the market expects negative abnormal returns, or positive abnormal returns in excess of about two percent in the long run are inconsistent with the market prices that we observe.

Since we use data for FoFs in our empirical analysis, our estimates of the expected abnormal return for the portfolio of unlisted PE investments includes any ability that FoFs might have in selecting unlisted PE funds, i.e. selection skill of FoFs, in 
addition to the ability of the average unlisted PE fund manager to outperform public equity, i.e. management skill. We cannot disentangle selection skill from management skill solely based on data for FoFs. But in a related context, Fung and Hseih (2000) find that the performance of hedge fund FoFs and the general population of hedge funds are about equal after accounting for selection bias in hedge fund databases and the fees of hedge fund FoFs. Their results indicate that FoFs exhibit little selection skill for hedge funds. To the extent that their findings can be generalized, the selection skill of FoFs for PE funds is unlikely to be a significant factor.

Both listed and unlisted private equity funds have betas close to one and they have positive betas on Fama-French SMB factor. Private equity fund returns exhibit positive correlation with GDP growth and negative correlation with credit spread, which proxies for business conditions. Finally, we find that market returns of listed fund of funds and listed private equity predict future changes in self-reported book values of unlisted private equity funds. 


\section{Appendix}

We assume that the CAPM determines the market value of each claim. The value of the base management fee, $V_{b, t}$, is the starting point of our analysis. Each period's base management fee is proportional to a stochastic process because a portion of the proceeds is reinvested. Hence, the appropriate discount rate, $E_{t}\left[R_{b}\right]$, depends on the retention ratio and the systematic risk of the underlying portfolio:

$$
V_{b, t}=E_{t}\left[\sum_{s=1}^{\infty} \frac{\lambda N A V_{t+s-1}}{\left(1+E_{t}\left[R_{b}\right]\right)^{s}}\right] .
$$

The present value of the fixed fees is proportional to the amount invested in the underlying portfolio, i.e. $V_{b, t}=\delta N A V_{t}$. We find the discount rate, $E_{t}\left[R_{b}\right]$, as well as the proportionality constant, $\delta$, starting from the following equation:

$$
\delta N A V_{t}=E_{t}\left[\frac{\lambda N A V_{t}+\delta N A V_{t+1}}{1+E_{t}\left[R_{b}\right]}\right] .
$$

We use the evolution of net asset value and rearrange this equation:

$$
\delta=E_{t}\left[\frac{\lambda+\delta\left(1+\theta\left(R_{u, t+1}-\lambda\right)\right)}{1+E_{t}\left[R_{b}\right]}\right] .
$$

Substituting the expected return for the underlying portfolio and rearranging again yields an expression for $E_{t}\left[R_{b}\right]$ in terms of:

$$
E_{t}\left[R_{b}\right]=\frac{\lambda}{\delta}+\theta\left(\alpha-\lambda+R_{f}+\beta_{u}\left(E_{t}\left[R_{m}\right]-R_{f}\right)\right) .
$$

Similarly, we write the actual return, $R_{b, t+1}$ :

$$
R_{b, t+1}=\frac{\lambda}{\delta}+\theta\left(\alpha-\lambda+R_{f}+\beta_{u}\left(R_{m, t+1}-R_{f}\right)+\varepsilon_{u, t+1}\right) .
$$

The systematic risk of the base fee, $\beta_{b}$, is equal to $\theta \beta_{u}$. Hence, the CAPM indicates

$$
E_{t}\left[R_{b}\right]=\frac{\lambda}{\delta}+\theta\left(\alpha-\lambda+R_{f}+\beta_{u}\left(E_{t}\left[R_{m}\right]-R_{f}\right)\right)=R_{f}+\theta \beta_{u}\left(E_{t}\left[R_{m}\right]-R_{f}\right) .
$$

The expected return is the riskfree rate plus an adjustment for the systematic riskiness of the fees based on reinvestment. In the absence of any reinvestment, the discount rate is $R_{f}$.

We rearrange to solve for $\delta$ as a function of the parameters:

$$
\delta=\frac{\lambda}{R_{f}-\theta\left(\alpha-\lambda+R_{f}\right)} .
$$

Therefore, the present value of the base management fee relative to net asset value and the associated discount rate are given by the following two equations:

$$
\frac{V_{b, t}}{N A V_{t}}=\frac{\lambda}{R_{f}-\theta\left(\alpha-\lambda+R_{f}\right)}
$$




$$
E_{t}\left[R_{b}\right]=R_{f}+\theta \beta_{u}\left(E_{t}\left[R_{m}\right]-R_{f}\right) .
$$

In the absence of any market inefficiencies, the price of the investors' claim $P_{t}$ is equal to the present value of the distributions to investors, $V_{e, t}$ :

$$
V_{e, t}=E_{t}\left[\sum_{s=1}^{\infty} \frac{(1-\theta-\pi)\left(R_{t+s}-\lambda\right) N A V_{t+s-1}}{\left(1+E_{t}\left[R_{e}\right]\right)^{s}}\right] .
$$

Analogously, the present value of the distributions to investors is proportional to the amount invested in the underlying portfolio, i.e. $V_{e, t}=\eta N A V_{t}$. We find the discount rate, $E_{t}\left[R_{e}\right]$, as well as the proportionality constant, $\eta$, starting from the following equation:

$$
\eta N A V_{t}=E_{t}\left[\frac{\lambda N A V_{t}+\delta N A V_{t+1}}{1+E_{t}\left[R_{e}\right]}\right] .
$$

Again, we use the evolution equation for net asset value and rearrange:

$$
\eta=E_{t}\left[\frac{(1-\theta-\pi)\left(R_{u, t+1}-\lambda\right)+\eta\left(1+\theta\left(R_{u, t+1}-\lambda\right)\right)}{1+E_{t}\left[R_{e}\right]}\right] .
$$

Substituting the expected return for the underlying portfolio and rearranging again yields an expression for $E_{t}\left[R_{e}\right]$ in terms of $\eta$.

$$
E_{t}\left[R_{e}\right]=\left(\frac{1-\theta-\pi}{\eta}+\theta\right)\left(\alpha-\lambda+R_{f}+\beta_{u}\left(E_{t}\left[R_{m}\right]-R_{f}\right)\right)
$$

Similarly, we write the actual return, $R_{e, t+1}$ :

$$
R_{e, t+1}=\left(\frac{1-\theta-\pi}{\eta}+\theta\right)\left(\alpha-\lambda+R_{f}+\beta_{u}\left(R_{m, t+1}-R_{f}\right)+\varepsilon_{u, t+1}\right) .
$$

The systematic risk of the base fee, $\beta_{b}$, is equal to $((1-\theta-\pi / \eta)+\theta) \beta_{u}$. Hence, the CAPM indicates

$$
\left(\frac{1-\theta-\pi}{\eta}+\theta\right)\left(\alpha-\lambda+R_{f}+\beta_{u}\left(E_{t}\left[R_{m}\right]-R_{f}\right)\right)=R_{f}+\left(\frac{1-\theta-\pi}{\eta}+\theta\right) \beta_{u}\left(E_{t}\left[R_{m}\right]-R_{f}\right) .
$$

We rearrange to solve for $\eta$ as a function of the parameters:

$$
\eta=\frac{(1-\theta-\pi)\left(\alpha-\lambda+R_{f}\right)}{R_{f}-\theta\left(\alpha-\lambda+R_{f}\right)} .
$$

Therefore, the present value of the distributions to investors relative to net asset value and the associated discount rate are given by the following two equations:

$$
\begin{gathered}
\frac{V_{e, t}}{N A V_{t}}=1-\frac{(1-\theta-\pi)\left(\alpha-\lambda+R_{f}\right)}{R_{f}-\theta\left(\alpha-\lambda+R_{f}\right)} \\
E_{t}\left[R_{e}\right]=R_{f}+\left(\frac{R_{f}}{\alpha-\lambda+R_{f}}\right) \beta_{u}\left(E_{t}\left[R_{m}\right]-R_{f}\right) .
\end{gathered}
$$




\section{References}

Bilo, S., H. Christophers, M. Degosciu, and H. Zimmermann, 2005, Risk, Returns, and Biases of Listed Private Equity Portfolios, WWZ Working Paper, No. 1/05, University of Basel.

Brophy D.J., and M.W. Guthner, 1988, Publicly Traded Venture Capital Funds: Implications for Institutional "Fund of Funds" Investors, Journal of Business Venturing 3, 187-206.

Carhart, M., 1997, On the Persistence of Mutual Fund Performance, Journal of Finance $52,57-82$.

Cochrane, J.H., 2005, The Risk and Return of Venture Capital, Journal of Financial Economics 75, 3-52.

Fama, E., 1990, Stock Returns, Expected Returns, and Real Activity, Journal of Finance 45, 1089-1108.

Fama, E., and K. French, 1993, Common Risk Factors in the Returns on Stocks and Bonds, Journal of Financial Economics 33, 3-56.

Gompers, P., and J. Lerner, 1999, An Analysis of Compensation in the U.S. Venture Capital Partnership, Journal of Financial Economics 51, 3-44.

Gompers, P., and J. Lerner, 2000, Money Chasing Deals? The Impact of Fund Inflows on Private Equity Valuations, Journal of Financial Economics 55, 281-325.

Hwang, M., J. Quigley, and S. Woodward, 2005, An Index for Venture Capital, 19872003, Contributions to Economic Analysis \& Policy 4, 1-43.

Jensen, M.C., 2007, The Economic Case For Private Equity, Unpublished Harvard NOM Research Paper No. 07-02.

Kaplan, S.N., and A. Schoar, 2005, Private Equity Performance: Returns, Persistence, and Capital Flows, Journal of Finance 60, 1791-1823.

Kaplan, S.N. and J.C. Stein, 1990, How Risky is the Debt in Highly Leveraged Transactions? Journal of Financial Economics 27, 215-245.

Koopman, S.J., R. Kräussl, A. Lucas, and A., Monteiro, 2009, Credit Cycles and Macro Fundamentals, Journal of Empirical Finance 16, 42-54. 
Ljungqvist, A., and M. Richardson, 2003, The Cash Flow, Return and Risk Characteristics of Private Equity, NBER Working Paper, \#9454.

Martin, J.D., and J.W. Petty, 1983, An Analysis of the Performance of Publicly Traded Venture Capital Companies, Journal of Financial and Quantitative Analysis 18, 401410.

Peng, L., 2001, Building a Venture Capital Index, ICF Working Paper, No. 00-51, Yale University.

Phalippou, L., and O. Gottschalg, 2009, The Performance of Private Equity Funds, Review of Financial Studies 22, 1747-1776.

Weiss, Kathleen, 1989, The Post-offering Price Performance of Closed-end Funds, Financial Management 18, 57-67. 


\section{Table 1a. Sample Statistics - Funds of Funds}

Notes: This table presents sample statistics for our sample of twenty-six private equity funds of funds (FoFs). The sample period is 1994 to 2008.

\begin{tabular}{|c|c|c|c|c|c|c|c|}
\hline \multicolumn{8}{|c|}{ Panel A: Exchange } \\
\hline & $\mathrm{N}$ & $\%$ & \% USD & Active & $\%$ & Dead & $\%$ \\
\hline US & 0 & $0.0 \%$ & $0.0 \%$ & 0 & $0.0 \%$ & 0 & $0.0 \%$ \\
\hline Europe & 14 & $53.9 \%$ & $68.9 \%$ & 14 & $53.9 \%$ & 0 & $0.0 \%$ \\
\hline London & 10 & $38.5 \%$ & $30.9 \%$ & 10 & $38.5 \%$ & 0 & $0.0 \%$ \\
\hline Australia & 2 & $7.7 \%$ & $0.3 \%$ & 1 & $3.9 \%$ & 1 & $3.8 \%$ \\
\hline Total & 26 & $100 \%$ & $100 \%$ & 25 & $96.2 \%$ & 1 & $3.8 \%$ \\
\hline \multicolumn{8}{|c|}{ Panel B: Size } \\
\hline & $\mathrm{N}$ & $\%$ & \% USD & Active & $\%$ & Dead & $\%$ \\
\hline$<20 \mathrm{~m}$ & 0 & $0.0 \%$ & $0.0 \%$ & 0 & $0.0 \%$ & 0 & $0.0 \%$ \\
\hline 20m - 100m & 7 & $26.9 \%$ & $2.9 \%$ & 6 & $23.1 \%$ & 1 & $3.8 \%$ \\
\hline 100m - 500m & 12 & $46.2 \%$ & $31.3 \%$ & 12 & $46.2 \%$ & 0 & $0.0 \%$ \\
\hline 500m - 1000m & 3 & $11.5 \%$ & $17.4 \%$ & 3 & $11.5 \%$ & 0 & $0.0 \%$ \\
\hline $1000 m-2500 m$ & 3 & $11.5 \%$ & $30.7 \%$ & 3 & $11.5 \%$ & 0 & $0.0 \%$ \\
\hline$>2500 \mathrm{~m}$ & 1 & $3.9 \%$ & $17.7 \%$ & 1 & $3.9 \%$ & 0 & $0.0 \%$ \\
\hline Total & 26 & $100 \%$ & $100 \%$ & 25 & $96.2 \%$ & 1 & $3.8 \%$ \\
\hline \multicolumn{8}{|c|}{ Panel C: Stage Focus } \\
\hline & Total & $\%$ & \% USD & Active & $\%$ & Dead & $\%$ \\
\hline Early-Stage & 2 & $7.7 \%$ & $2.3 \%$ & 2 & $7.7 \%$ & 0 & $0.0 \%$ \\
\hline Expansion & 2 & $7.7 \%$ & $2.2 \%$ & 2 & $7.7 \%$ & 0 & $0.0 \%$ \\
\hline Balanced & 0 & $0.0 \%$ & $0.0 \%$ & 0 & $0.0 \%$ & 0 & $0.0 \%$ \\
\hline Buyout & 20 & $76.9 \%$ & $87.7 \%$ & 19 & $73.1 \%$ & 1 & $3.8 \%$ \\
\hline Other PE & 2 & $7.7 \%$ & $7.8 \%$ & 2 & $7.7 \%$ & 0 & $0.0 \%$ \\
\hline Total & 26 & $100 \%$ & $100 \%$ & 25 & $96.2 \%$ & 1 & $3.8 \%$ \\
\hline \multicolumn{8}{|c|}{ Panel D: Geographical Focus } \\
\hline & $\mathrm{N}$ & $\%$ & $\%$ USD & Active & $\%$ & Dead & $\%$ \\
\hline North America & 11 & $42.3 \%$ & $68.6 \%$ & 11 & $42.3 \%$ & 0 & $0.0 \%$ \\
\hline Europe & 11 & $42.3 \%$ & $29.2 \%$ & 11 & $42.3 \%$ & 0 & $0.0 \%$ \\
\hline Rest of the World & 4 & $15.4 \%$ & $2.3 \%$ & 3 & $11.5 \%$ & 1 & $3.8 \%$ \\
\hline Total & 26 & $100.0 \%$ & $100.0 \%$ & 25 & $96.2 \%$ & 1 & $3.8 \%$ \\
\hline
\end{tabular}




\section{Table 1b: Descriptive Statistics - Funds of Funds}

Notes: This table reports descriptive statistics for twenty-six funds of funds (FoFs) for the period 1994 to 2008. The first column for every variable shows the median while the second shows the average. Market capitalization is the number of shares outstanding multiplied by price per share in millions of USD. Institutional ownership is the percentage of outstanding shares for each FoF held by institutional investors. Underlying PE Funds is the number of distinct unlisted PE funds held by the FoF.

\begin{tabular}{lcc}
\hline & Median & Average \\
\hline Market Capitalization & 203.8 & 312.4 \\
& & \\
Base Management Fee & $1.50 \%$ & $1.40 \%$ \\
Incentive Fee & $10.00 \%$ & $10.73 \%$ \\
Hurdle rate & $8.00 \%$ & $9.54 \%$ \\
& & \\
Institutional Ownership & $46.59 \%$ & $47.15 \%$ \\
Underlying PE Funds & 28 & 42 \\
\hline
\end{tabular}




\section{Table 2. Sample Statistics - Listed Private Equity Funds}

Notes: This table presents the sample statistics for our sample of 129 listed private equity funds (LPEs). The sample period is 1994 to 2008.

\begin{tabular}{|c|c|c|c|c|c|c|c|}
\hline \multicolumn{8}{|c|}{ Panel A: Exchange } \\
\hline & $\mathrm{N}$ & $\%$ & \% USD & Active & $\%$ & Dead & $\%$ \\
\hline US & 16 & $12.4 \%$ & $59.3 \%$ & 16 & $12.4 \%$ & 0 & $0.0 \%$ \\
\hline Europe & 7 & $5.4 \%$ & $0.9 \%$ & 5 & $3.9 \%$ & 2 & $1.6 \%$ \\
\hline London & 92 & $71.3 \%$ & $32.7 \%$ & 81 & $62.8 \%$ & 11 & $8.5 \%$ \\
\hline Rest of the World & 14 & $10.9 \%$ & $7.1 \%$ & 9 & $7.0 \%$ & 5 & $3.9 \%$ \\
\hline Total & 129 & $100.0 \%$ & $100.0 \%$ & 111 & $86.1 \%$ & 18 & $14.0 \%$ \\
\hline \multicolumn{8}{|c|}{ Panel B: Size } \\
\hline & $\mathrm{N}$ & $\%$ & \% USD & Active & $\%$ & Dead & $\%$ \\
\hline$<20 \mathrm{~m}$ & 28 & $21.7 \%$ & $1.3 \%$ & 22 & $17.1 \%$ & 6 & $4.7 \%$ \\
\hline $20 m-100 m$ & 67 & $51.9 \%$ & $11.2 \%$ & 57 & $44.2 \%$ & 10 & $7.8 \%$ \\
\hline 100m - 500m & 26 & $20.2 \%$ & $31.2 \%$ & 25 & $19.4 \%$ & 1 & $0.8 \%$ \\
\hline $500 m-1000 m$ & 5 & $3.9 \%$ & $11.6 \%$ & 4 & $3.1 \%$ & 1 & $0.8 \%$ \\
\hline 1000m - 2500 & 0 & $0.0 \%$ & $0.0 \%$ & 0 & $0.0 \%$ & 0 & $0.0 \%$ \\
\hline$>2500 \mathrm{~m}$ & 3 & $2.3 \%$ & $44.7 \%$ & 3 & $2.3 \%$ & 0 & $0.0 \%$ \\
\hline Total & 129 & $100.0 \%$ & $100.0 \%$ & 111 & $86.1 \%$ & 18 & $14.0 \%$ \\
\hline \multicolumn{8}{|c|}{ Panel C: Stage Focus } \\
\hline & $\mathrm{N}$ & $\%$ & \% USD & Active & $\%$ & Dead & $\%$ \\
\hline Early-Stage & 25 & $19.4 \%$ & $4.7 \%$ & 18 & $14.0 \%$ & 7 & $5.4 \%$ \\
\hline Expansion & 34 & $26.4 \%$ & $26.0 \%$ & 30 & $23.3 \%$ & 4 & $3.1 \%$ \\
\hline Balanced & 44 & $34.1 \%$ & $13.8 \%$ & 40 & $31.0 \%$ & 4 & $3.1 \%$ \\
\hline Buyout & 13 & $10.1 \%$ & $13.4 \%$ & 11 & $8.5 \%$ & 2 & $1.6 \%$ \\
\hline Other PE & 13 & $10.1 \%$ & $42.1 \%$ & 12 & $9.3 \%$ & 1 & $0.8 \%$ \\
\hline Total & 129 & $100.0 \%$ & $100.0 \%$ & 111 & $86.1 \%$ & 18 & $14.0 \%$ \\
\hline \multicolumn{8}{|c|}{ Panel D: Geographical Focus } \\
\hline & $\mathrm{N}$ & $\%$ & \% USD & Active & $\%$ & Dead & $\%$ \\
\hline North America & 17 & $13.2 \%$ & $46.0 \%$ & 17 & $13.2 \%$ & 0 & $0.0 \%$ \\
\hline Europe & 78 & $60.5 \%$ & $21.4 \%$ & 68 & $52.7 \%$ & 10 & $7.8 \%$ \\
\hline Rest of the World & 34 & $26.4 \%$ & $32.6 \%$ & 26 & $20.2 \%$ & 8 & $6.2 \%$ \\
\hline Total & 129 & $100.0 \%$ & $100.0 \%$ & 111 & $86.1 \%$ & 18 & $14.0 \%$ \\
\hline
\end{tabular}




\section{Table 3. FoF Discount in Event Time}

Notes: This table reports the average fund discounts in event time for exchange-traded funds of funds (FoFs) that invest in unlisted private equity funds. Event month 1 is the first month after the initial public offering; event month 2 is the second month, and so on.

\begin{tabular}{c|ccc} 
Event Month & Average Discount & Standard Error & t-statistic \\
\hline 1 & $-3.06 \%$ & $0.52 \%$ & -5.93 \\
2 & $0.63 \%$ & $1.84 \%$ & 0.34 \\
3 & $2.87 \%$ & $1.79 \%$ & 1.60 \\
4 & $5.47 \%$ & $1.88 \%$ & 2.91 \\
5 & $7.72 \%$ & $2.04 \%$ & 3.78 \\
6 & $7.50 \%$ & $2.60 \%$ & 2.89 \\
7 & $8.77 \%$ & $2.50 \%$ & 3.51 \\
8 & $10.37 \%$ & $2.79 \%$ & 3.71 \\
9 & $10.57 \%$ & $2.58 \%$ & 4.10 \\
10 & $11.64 \%$ & $2.74 \%$ & 4.24 \\
11 & $12.09 \%$ & $2.85 \%$ & 4.24 \\
12 & $11.54 \%$ & $3.53 \%$ & 3.27 \\
\hline
\end{tabular}




\section{Table 4. Simulated FoF Discount}

Notes: This table reports the average (across funds) of the simulated FoF discount for each particular combination of the payout ratio and the expected abnormal return. We calculate the discount for each fund as unity minus the average simulated present value of all distributions to investors divided by the initial NAV of the fund. We compute the relevant present value of FoF equity separately for each FoF using the fundspecific fee structure. These calculations are based on 5,000 fund-specific performance simulations. The simulation methodology is discussed in greater detail in the text. The expected abnormal return $(\alpha)$ is the market's expectation of the abnormal return for the underlying portfolio of PE investments. The payout ratio is the fraction of a fund's earnings that is paid out to equity holders.

\begin{tabular}{c|ccccc} 
Payout Ratio (1- $\boldsymbol{\theta})$ & \multicolumn{5}{|c}{ Expected Abnormal Return $(\boldsymbol{\alpha})$} \\
& $\mathbf{- 2 \%}$ & $\mathbf{- 1 \%}$ & $\mathbf{0}$ & $\mathbf{1 \%}$ & $\mathbf{2 \%}$ \\
\hline $\mathbf{0 . 2 5}$ & $62.52 \%$ & $53.19 \%$ & $40.09 \%$ & $18.29 \%$ & $-17.91 \%$ \\
$\mathbf{0 . 5 0}$ & $43.94 \%$ & $34.97 \%$ & $24.09 \%$ & $10.69 \%$ & $-6.13 \%$ \\
$\mathbf{0 . 7 5}$ & $33.99 \%$ & $26.01 \%$ & $17.72 \%$ & $7.35 \%$ & $-3.41 \%$ \\
$\mathbf{1}$ & $27.65 \%$ & $20.78 \%$ & $13.49 \%$ & $6.03 \%$ & $-2.29 \%$ \\
\hline
\end{tabular}




\section{Table 5: LPE Discount in Event Time}

Notes: This table reports the average discount in event time for listed private equity funds. Event month 1 is the first month after the initial public offering; event month 2 is the second month, and so on.

\begin{tabular}{c|ccc} 
Event Month & Average Discount & Standard Error & $\boldsymbol{t}$-statistic \\
\hline 1 & $-4.08 \%$ & $1.87 \%$ & -2.18 \\
2 & $-4.48 \%$ & $2.00 \%$ & -2.24 \\
3 & $-3.31 \%$ & $2.11 \%$ & -1.57 \\
4 & $-3.76 \%$ & $1.98 \%$ & -1.90 \\
5 & $-2.66 \%$ & $2.16 \%$ & -1.23 \\
6 & $-1.88 \%$ & $2.12 \%$ & -0.89 \\
7 & $-1.70 \%$ & $2.15 \%$ & -0.79 \\
8 & $-1.52 \%$ & $2.12 \%$ & -0.72 \\
9 & $1.54 \%$ & $2.30 \%$ & 0.67 \\
10 & $-0.04 \%$ & $2.22 \%$ & -0.02 \\
11 & $0.96 \%$ & $2.13 \%$ & 0.45 \\
12 & $1.74 \%$ & $2.26 \%$ & 0.77 \\
\hline
\end{tabular}




\section{Table 6. The Performance of Private Equity (CAPM)}

Notes: This table reports market model regression estimates for value weighted FoF and LPE indices. We use MSCI World or S\&P 500 indices as market proxies. One-month Treasury bill rate is the riskfree rate. The dependent variables are excess returns on the indices reported in the column headings. The standard errors are based on the Newey-West estimator with 6 lags (in parentheses). The sample period is from January 1994 to December 2008.

\begin{tabular}{l|cccc} 
& FoF & FoF & LPE & LPE \\
\hline Intercept & 0.0002 & -0.0005 & -0.0017 & -0.0023 \\
& $(0.0051)$ & $(0.0058)$ & $(0.0035)$ & $(0.0042)$ \\
MSCI World & $0.9227^{* * *}$ & & $0.8384^{* * *}$ & \\
& $(0.1956)$ & & $(0.1827)$ & $0.7071^{* * *}$ \\
S\&P 500 & & $0.7999 * * *$ & & $(0.2026)$ \\
& & $(0.2128)$ & & 0.2851 \\
$R^{2}$ & 0.3881 & 0.3043 & 0.3843 & 180 \\
Observations & 180 & 180 & 180 & \\
\hline
\end{tabular}

*** - Significant at the $1 \%$ level. 
Table 7. The Performance of Private Equity (4-Factor Model)

Notes: This table reports the four-factor model estimates for value-weighted FOFs and LPE indices. We use MSCI World or S\&P 500 indices as market proxies. One-month treasury rate is the riskfree rate. SMB and HML Fama-French size and book-to-market factors, respectively, and UMD is momentum factor. The dependent variables are excess returns on the indices reported in the column headings. The standard errors are based on the Newey-West estimator with 6 lags (in parentheses). The sample period is from January 1994 to December 2008.

\begin{tabular}{l|cccc} 
& FoF & FoF & LPE & LPE \\
\hline Intercept & -0.0023 & -0.0038 & -0.0045 & -0.0058 \\
& $(0.0060)$ & $(0.0068)$ & $(0.0041)$ & $(0.0048)$ \\
MSCI World & $0.9943^{* * *}$ & & $0.9093^{* * *}$ & \\
& $(0.2272)$ & & $(0.1924)$ & \\
S\&P 500 & & $0.9244^{* * *}$ & & $0.8338^{* * * *}$ \\
& & $(0.2498)$ & & $(0.2173)$ \\
SMB & $0.4354 * * *$ & $0.5421^{* * *}$ & $0.5389 * * *$ & $0.6349 * * *$ \\
& $(0.1344)$ & $(0.1532)$ & $(0.1463)$ & $(0.1648)$ \\
HML & 0.3529 & 0.3912 & $0.3949 *$ & $0.4236^{*}$ \\
& $(0.2192)$ & $(0.2470)$ & $(0.2221)$ & $(0.2426)$ \\
MOM & 0.0609 & 0.0876 & 0.0543 & 0.0756 \\
& $(0.0786)$ & $(0.0895)$ & $(0.0566)$ & $(0.0540)$ \\
$R^{2}$ & 0.4507 & 0.3954 & 0.4937 & 0.4299 \\
Observations & 180 & 180 & 180 & 180 \\
\hline
\end{tabular}

* - Significant at the $10 \%$ level.

*** - Significant at the $1 \%$ level. 


\section{Table 8. The Impact of the Macroeconomic Environment on the Performance of Private Equity}

Notes: This table reports the estimates of a regression of excess returns on value-weighted FoFs and LPE indices on MSCI world index, GDP growth and credit spread. One month Treasury bill rate is the riskfree rate. Both GDP growth and the credit spread are de-meaned and scaled by their standard deviations. The dependent variables are excess returns on the indices reported in the column headings. The standard errors are based on the Newey-West estimator with 6 lags (in parentheses). The sample period is from January 1994 to December 2008.

Dependent Variable: LPE Index Excess Return

\begin{tabular}{|c|c|c|c|c|c|c|}
\hline & FoF & FoF & FoF & LPE & LPE & LPE \\
\hline Intercept & $\begin{array}{c}0.0004 \\
(0.0037)\end{array}$ & $\begin{array}{c}0.0006 \\
(0.0038)\end{array}$ & $\begin{array}{c}0.0006 \\
(0.0034)\end{array}$ & $\begin{array}{l}-0.0012 \\
(0.0028)\end{array}$ & $\begin{array}{l}-0.0015 \\
(0.0028)\end{array}$ & $\begin{array}{l}-0.0015 \\
(0.0027)\end{array}$ \\
\hline MSCI World & $\begin{array}{c}0.7961 * * * \\
(0.1142)\end{array}$ & $\begin{array}{c}0.7270 * * * \\
(0.1066)\end{array}$ & $\begin{array}{c}0.7101 * * * \\
(0.0972)\end{array}$ & $\begin{array}{c}0.7587 * * * \\
(0.1335)\end{array}$ & $\begin{array}{c}0.7152 * * * \\
(0.1163)\end{array}$ & $\begin{array}{c}0.7045 * * * \\
(0.1152)\end{array}$ \\
\hline GDP growth & $\begin{array}{c}0.0204 * * \\
(0.0079)\end{array}$ & & $\begin{array}{l}0.0087^{*} \\
(0.0045)\end{array}$ & $\begin{array}{c}0.0129 * * \\
(0.0050)\end{array}$ & & $\begin{array}{l}0.0055^{*} \\
(0.0029)\end{array}$ \\
\hline Credit spread & & $\begin{array}{c}-0.0261 * * * \\
(0.0049)\end{array}$ & $\begin{array}{c}-0.0212 * * * \\
(0.0051)\end{array}$ & & $\begin{array}{c}-0.0166 * * * \\
(0.0041)\end{array}$ & $\begin{array}{c}-0.0133 * * * \\
(0.0040)\end{array}$ \\
\hline$R^{2}$ & 0.4874 & 0.5458 & 0.5583 & 0.4318 & 0.4594 & 0.4654 \\
\hline Observations & 180 & 180 & 180 & 180 & 180 & 180 \\
\hline
\end{tabular}

* - Significant at the $10 \%$ level.

** - Significant at the 5\% level.

*** - Significant at the $1 \%$ level. 


\section{Table 9. Lead-Lag Relation for the Private Equity Performance Index (PEPI) and the FoF, LPE and MSCI World Indices}

Notes: This table examines the lead-lag relation between the performance for the PEPI in the United States and the returns for the FoF, LPE and MSCI World indices. The dependent variable is the quarterly return on PEPI for the United States, reported by Thomson Reuters and the National Venture Capital Association (NVCA) from Q1 of 1994 until Q3 of 2008. MSCI World is the return to the MSCI World index. The FoFs is the value-weight return on the index of listed funds of funds that invest in unlisted private equity funds. The standard errors are based on the NeweyWest estimator with 6 lags (in parentheses).

\section{Dependent Variable: Private Equity Performance Index (PEPI) Return}

\begin{tabular}{|c|c|c|c|c|c|c|}
\hline & 1 & 2 & 3 & 4 & 5 & 6 \\
\hline Intercept & $\begin{array}{c}0.0153 * * \\
(0.0062)\end{array}$ & $\begin{array}{c}0.0149 * * \\
(0.0062)\end{array}$ & $\begin{array}{c}0.0137 * * \\
(0.0054)\end{array}$ & $\begin{array}{l}0.0122 * \\
(0.0062)\end{array}$ & $\begin{array}{l}0.0093^{*} \\
(0.0048)\end{array}$ & $\begin{array}{c}0.0088 * * \\
(0.0045)\end{array}$ \\
\hline MSCI World & $\begin{array}{c}0.3863 * * * \\
(0.0469)\end{array}$ & & $\begin{array}{c}0.2677 * * * \\
(0.0444)\end{array}$ & & $\begin{array}{c}0.3355 * * * \\
(0.0407)\end{array}$ & $\begin{array}{c}0.3480 * * * \\
(0.0350)\end{array}$ \\
\hline MSCI World (Lag) & & & & & & $\begin{array}{l}0.0867 * \\
(0.0526)\end{array}$ \\
\hline LPE FoFs & & $\begin{array}{c}0.2593 * * * \\
(0.0244)\end{array}$ & $\begin{array}{c}0.1268 * * * \\
(0.0270)\end{array}$ & $\begin{array}{c}0.2381 * * * \\
(0.0235)\end{array}$ & $\begin{array}{c}0.0596 * * \\
(0.0249)\end{array}$ & $\begin{array}{c}0.0476 * * \\
(0.0217)\end{array}$ \\
\hline LPE FoFs (Lag) & & & & $\begin{array}{c}0.0925^{* *} \\
(0.0408)\end{array}$ & $\begin{array}{c}0.1450 * * * \\
(0.0316)\end{array}$ & $\begin{array}{c}0.1071 * * * \\
(0.0355)\end{array}$ \\
\hline$R^{2}$ & 0.4879 & 0.4152 & 0.5414 & 0.4604 & 0.6439 & 0.6565 \\
\hline Observations & 59 & 59 & 59 & 58 & 58 & 58 \\
\hline
\end{tabular}

* - Significant at the $10 \%$ level.

** - Significant at the 5\% level.

$* * *$ - Significant at the $1 \%$ level. 
Figure 1. The Expected Abnormal Return and Market Value vs. Book Value of PE Investments

Panel A: Expected Abnormal Return > 0

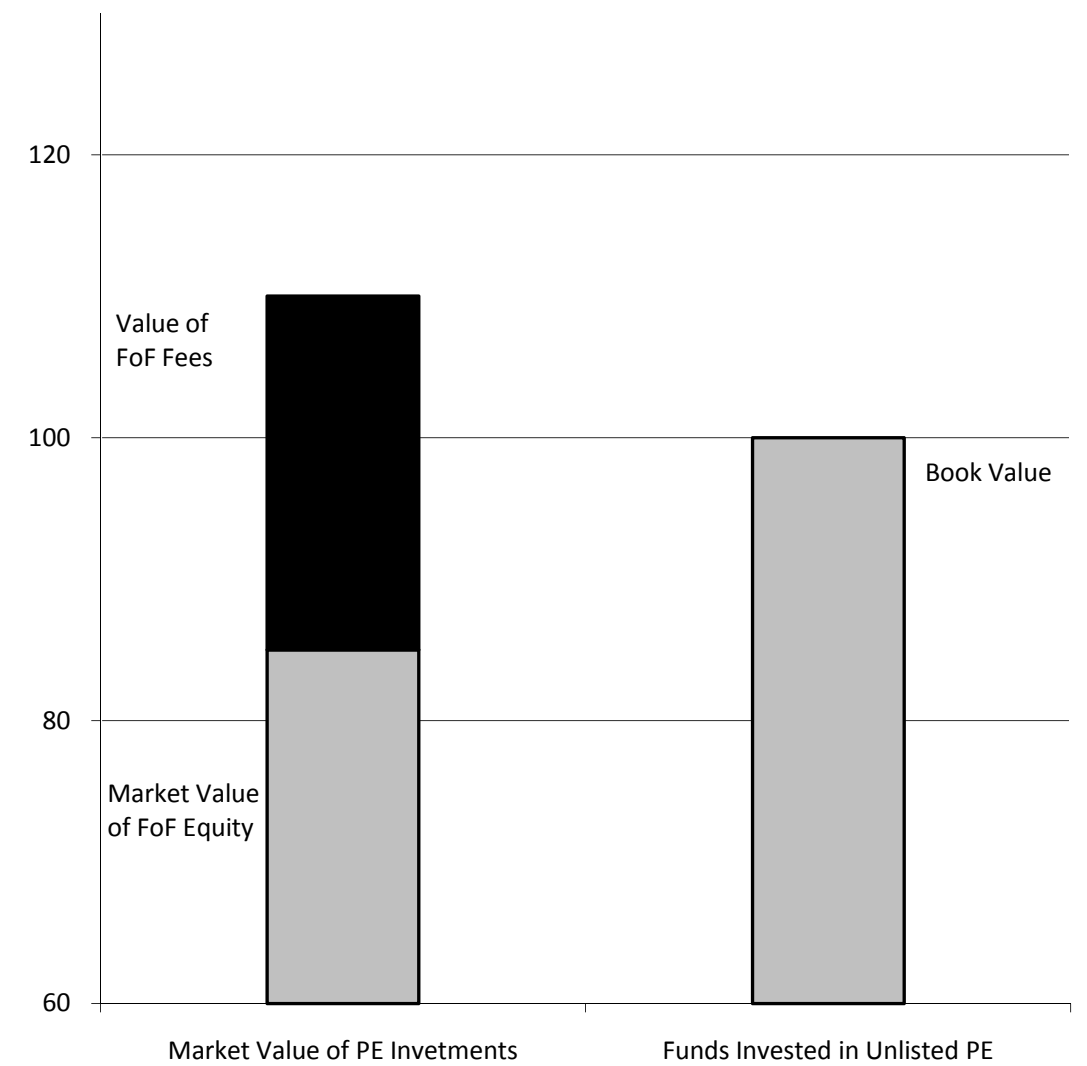

Panel B: Expected Abnormal Return $<0$

120

100

80

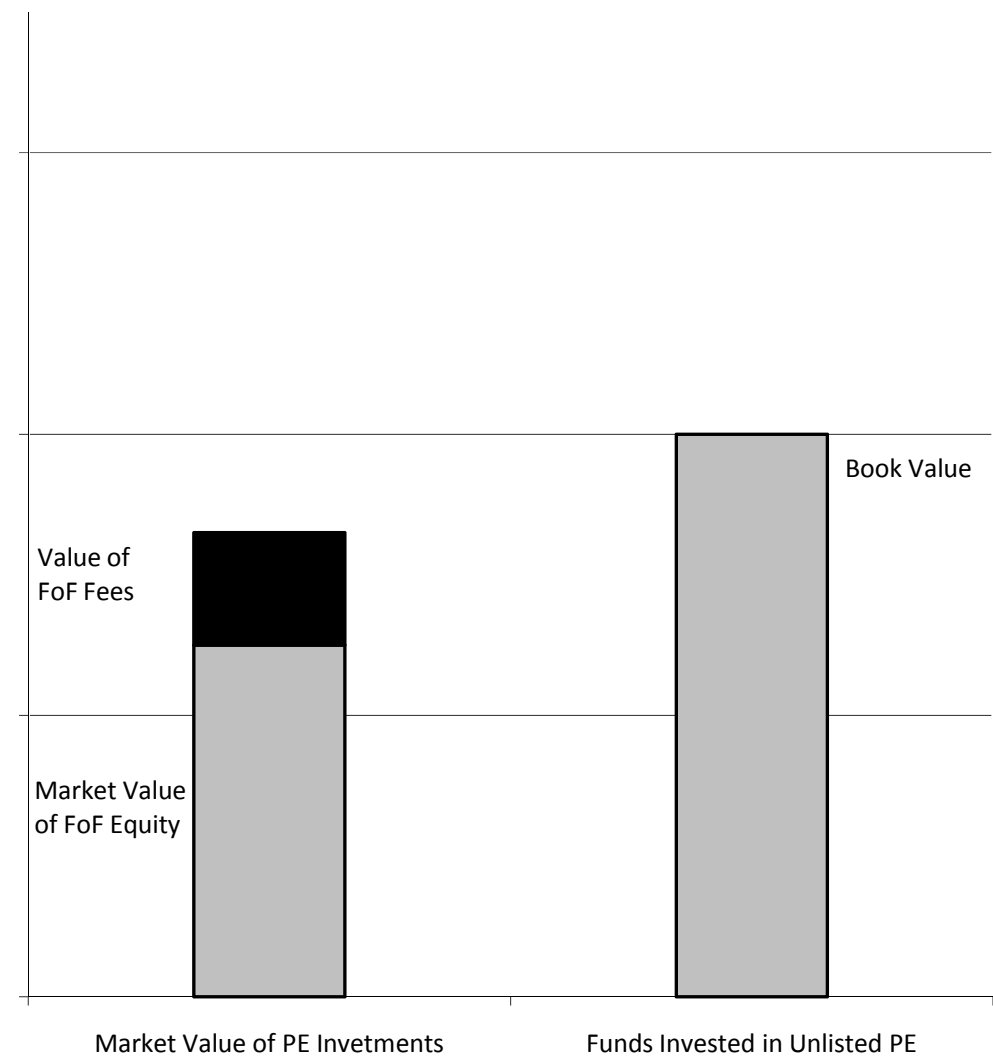


Figure 2. Upper and Lower Bounds for the Expected Abnormal Return

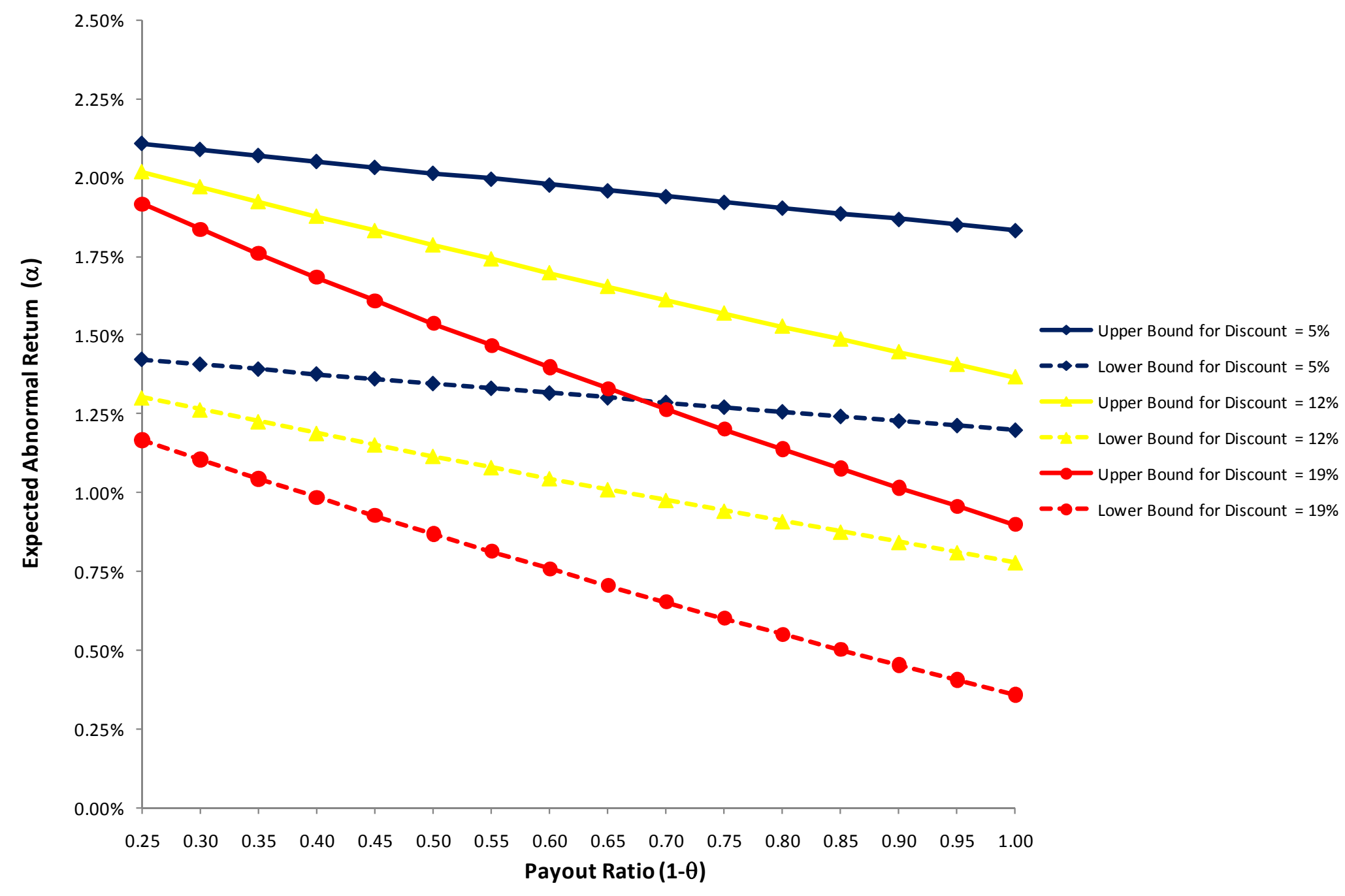

Notes: This figure presents the upper and lower bounds for the expected abnormal return ( $\alpha$ ) for three different levels of the FoF discount: 5\%, 12\%, and 19\%. These three levels reflect the point estimate and the end points of the 95\% confidence interval for the average FoF discount twelve months after the initial public offering (see Table 3). The bounds for the expected abnormal return are determined by equations (9) and (10) in Section III.A.3 discussing the model. 
Figure 3. Simulated Relation for the Discount and the Expected Abnormal Return

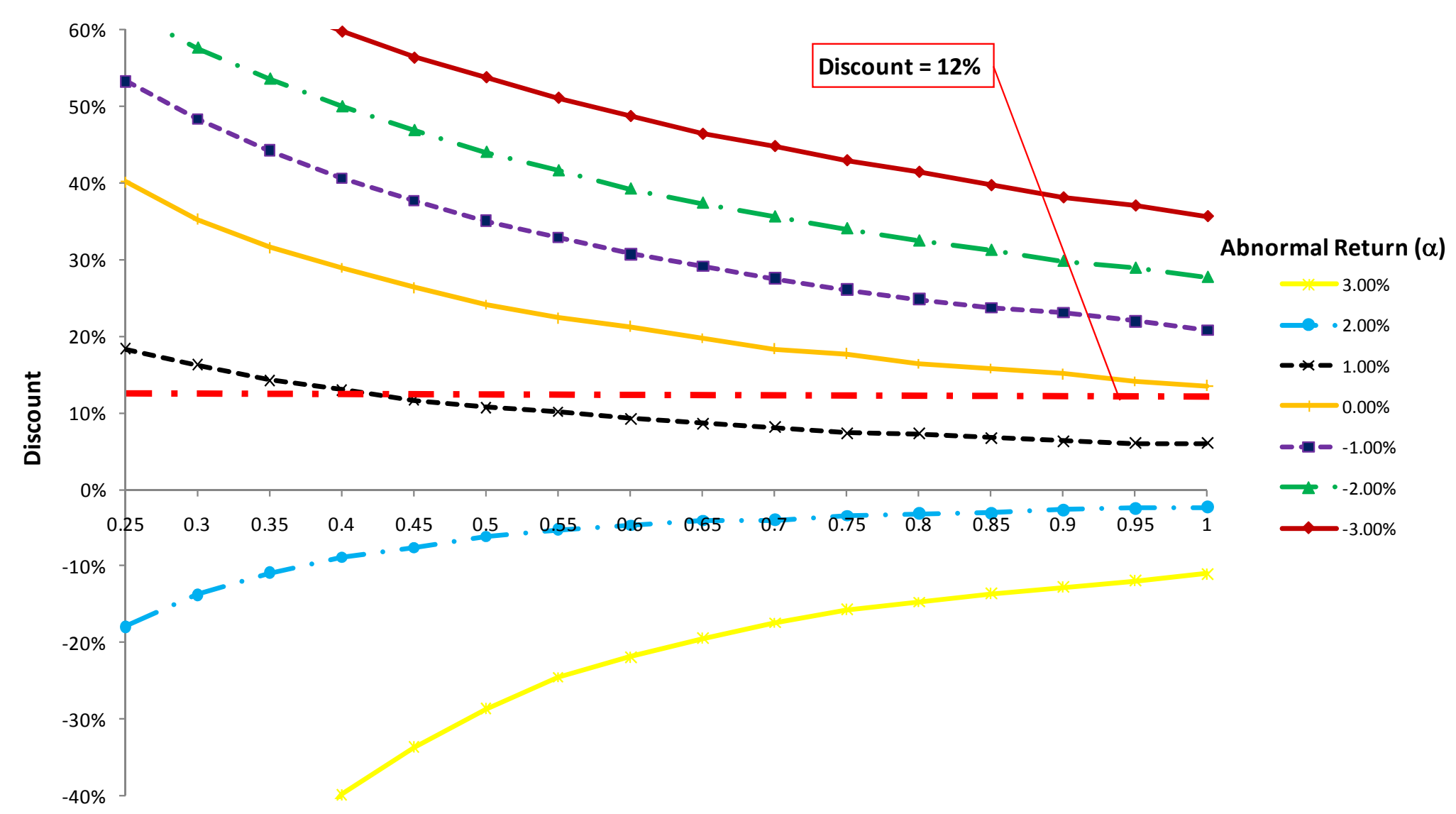

Payout Ratio (1- $\theta)$

Notes: This figure presents the simulated relation between the average (across funds) FoF discount and payout ratios for different levels of the expected abnormal return $(\alpha)$. The line labeled Discount $=12 \%$ plots the average discount observed in the sample one year after the initial public offerings for the funds of funds. We calculate the discount for each fund as unity minus the average simulated present value of all distributions to investors divided by the initial NAV of the fund. The expected abnormal return is the market's expectation of the abnormal return for the underlying portfolio of PE investments. The simulation methodology is discussed in greater detail in the text. 